\title{
Magnetic order in 3D topological insulators -Wishful thinking or gateway to emergent quantum effects?
}

Cite as: Appl. Phys. Lett. 117, 150502 (2020); https://doi.org/10.1063/5.0027987

Submitted: 02 September 2020 . Accepted: 24 September 2020 . Published Online: 14 October 2020

(D) A. I. Figueroa, (D) T. Hesjedal, and (D) N.-J. Steinke

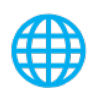

\section{ARTICLES YOU MAY BE INTERESTED IN}

Quantum neuromorphic computing

Applied Physics Letters 117, 150501 (2020); https://doi.org/10.1063/5.0020014

A perspective on hybrid quantum opto- and electromechanical systems

Applied Physics Letters 117, 150503 (2020); https://doi.org/10.1063/5.0021088

Quantum anomalous Hall effect driven by magnetic proximity coupling in all-telluride based heterostructure

Applied Physics Letters 115, 102403 (2019); https://doi.org/10.1063/1.5111891

Challenge us.

What are your needs for periodic signal detection?

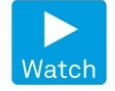

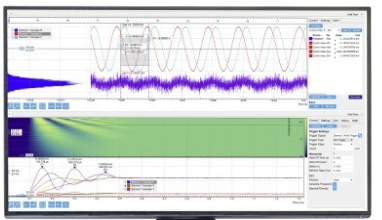

0
Zurich

Instruments 


\title{
Magnetic order in 3D topological insulators-Wishful thinking or gateway to emergent quantum effects?
}

Cite as: Appl. Phys. Lett. 117, 150502 (2020); doi: 10.1063/5.0027987

Submitted: 2 September 2020 - Accepted: 24 September 2020 . Published Online: 14 October 2020 - Corrected: 21 October 2020
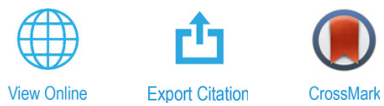

A. I. Figueroa, ${ }^{1, a)}$ (D) T. Hesjedal, ${ }^{2, a)}$ (iD and N.-J. Steinke ${ }^{3, a)}$ (iD

\begin{abstract}
AFFILIATIONS
${ }^{7}$ Catalan Institute of Nanoscience and Nanotechnology (ICN2), CSICand BIST, Campus UAB, Barcelona 08193, Spain

${ }^{2}$ Clarendon Laboratory, Department of Physics, University of Oxford, Parks Road, Oxford OX1 3PU, United Kingdom

${ }^{3}$ Institut Laue-Langevin, 71 Avenue des Martyrs, 38000 Grenoble, France
\end{abstract}

${ }^{a)}$ Authors to whom correspondence should be addressed: adriana.figueroa@icn2.cat; Thorsten.Hesjedal@physics.ox.ac.uk; and steinkenj@ill.eu

\begin{abstract}
Three-dimensional topological insulators (TIs) are a perfectly tuned quantum-mechanical machinery in which counterpropagating and oppositely spin-polarized conduction channels balance each other on the surface of the material. This topological surface state crosses the bandgap of the TI and lives at the interface between the topological and a trivial material, such as vacuum. Despite its balanced perfection, it is rather useless for any practical applications. Instead, it takes the breaking of time-reversal symmetry (TRS) and the appearance of an exchange gap to unlock hidden quantum states. The quantum anomalous Hall effect, which has first been observed in $\mathrm{Cr}$-doped $(\mathrm{Sb}, \mathrm{Bi})_{2} \mathrm{Te}{ }_{3}$, is an example of such a state in which two edge channels are formed at zero field, crossing the magnetic exchange gap. The breaking of TRS can be achieved by magnetic doping of the TI with transition metal or rare earth ions, modulation doping to keep the electronically active channel impurity free, or proximity coupling to a magnetically ordered layer or substrate in heterostructures or superlattices. We review the challenges these approaches are facing in the famous $3 \mathrm{D} \mathrm{TI}(\mathrm{Sb}, \mathrm{Bi})_{2}(\mathrm{Se}, \mathrm{Te})_{3}$ family and try to answer the question whether these materials can live up to the hype surrounding them.
\end{abstract}

Published under license by AIP Publishing. https://doi.org/10.1063/5.0027987

Prototypical three-dimensional (3D) topological insulators (TIs) ${ }^{1}$ of the $(\mathrm{Bi}, \mathrm{Sb})_{2}(\mathrm{Se}, \mathrm{Te})_{3}$ family of solid solutions, most notably $\mathrm{Bi}_{2} \mathrm{Se}_{3}$, $\mathrm{Bi}_{2} \mathrm{Te}_{3}$, and $\mathrm{Sb}_{2} \mathrm{Te}_{3}$, had a successful career as efficient thermoelectric materials ${ }^{2,3}$ before the theoretical prediction of their topological surface states (TSSs) in $2009 .^{4}$ The TSS results from their large spin-orbit coupling and is made up of spin-momentum locked, counterpropagating streams of oppositely spin-polarized electrons. Elastic backscattering by nonmagnetic impurities is forbidden by time-reversal symmetry (TRS), in principle resulting in high carrier mobilities. The existence of the gapless TSS in 3D TIs was first experimentally demonstrated using angle-resolved photoemission spectroscopy, ${ }^{5}$ instead of, as one might have expected, in transport measurements. The reason lies in the rather poor electronic properties of $(\mathrm{Bi}, \mathrm{Sb})_{2}(\mathrm{Se}, \mathrm{Te})_{3}$-based materials, which are in fact narrow-gap semiconductors with strong, unintentional charge doping due to chalcogen vacancies. These high levels of bulk carriers can be most efficiently overcome by counterdoping, ${ }^{6}$ in particular in very thin films in which the relative bulk carrier concentration is naturally suppressed.
In order to observe the exciting physical phenomena TIs are synonymous for, such as the quantum anomalous Hall effect (QAHE), the topological magnetoelectric effect, ${ }^{8}$ the physics related to chiral edge states, ${ }^{9}$ and spintronic effects, ${ }^{10}$ TRS has to be broken and an exchange gap introduced in the TI. ${ }^{11}$ The exchange gap was initially achieved by direct magnetic doping of the TI, by both transitionmetals and rare-earth ions, in bulk crystals as well as thin films. ${ }^{12-20}$ The QAHE was recently observed in the intrinsic magnetic TI $\mathrm{MnBi}_{2} \mathrm{Te}_{4}{ }^{21}$ Proximity-coupling to magnetically ordered substrates or layers, i.e., ferromagnets, ferrimagnets, or antiferromagnets, is another way to break TRS. One inherent advantage of this approach is that there are no dopants interfering with the electrically active part of the TI, which could be compromised by the added impurities. Finally, the combination of the different approaches in the form of heterostructures and superlattices opens up new ways to achieve efficient TRS breaking without, in principle, compromising the electronic properties of the TI too much. Nevertheless, neither approach is yielding an observable QAHE at decent (liquid $\mathrm{He}$ and above) temperatures 
despite the fact the TSS is observable at room temperature. On the other hand, the magnetic transition temperature $T_{\mathrm{C}}$ itself is not setting the limit either; in fact, it can reach very high values. For instance, $\mathrm{Cr}_{0.15}\left(\mathrm{Bi}_{0.1} \mathrm{Sb}_{0.9}\right)_{1.85} \mathrm{Te}_{3}$, which has been the most successful QAHE system so far, has a $T_{\mathrm{C}}$ of $16 \mathrm{~K}$, whereas very low temperatures $(<300 \mathrm{mK})$ are required to observe the QAHE.

There are several outstanding recent reviews of magnetic TIs, their exotic phenomena, and applications, which can be found in Refs. 24-26. In this review, we focus on the discussion of the various growth and doping approaches for achieving an exchange gap in TI thin films, with a particular emphasis on heterostructures, and we finally try to answer the question whether there is hope for these materials to fulfill their star potential.

In the context of thermoelectric applications and fundamental studies of the $(\mathrm{Bi}, \mathrm{Sb})_{2}(\mathrm{Se}, \mathrm{Te})_{3}$ family of solid solutions, a number of single crystal, ${ }^{27,28}$ nanostructure, ${ }^{29-34}$ and thin film growth techniques have been employed; ${ }^{35-40}$ however, for brevity and also given the versatility of the method, our review focuses solely on results obtained using molecular beam epitaxy $(\mathrm{MBE})^{41,42}$ (for reviews on TI thin film growth, see, e.g., Refs. 43-45). High-quality single crystalline TI thin film growth by MBE has been reported on a wide variety of singlecrystalline substrates, e.g., $\mathrm{Si}^{46-51} \mathrm{Al}_{2} \mathrm{O}_{3},{ }^{52-56} \mathrm{GaAs},{ }^{57-60} \mathrm{Ge},{ }^{61,62}$ $\mathrm{CdS},{ }^{63} \mathrm{SrTiO}_{3},{ }^{64}$ graphene (on $6 \mathrm{H}-\mathrm{SiC}$ ), ${ }^{65}$ lattice-matched $\mathrm{InP},{ }^{66,67}$ and $\mathrm{BaF}_{2},{ }^{68}$ as well as amorphous $\mathrm{SiO}_{2} / \mathrm{Si}$ for back-gated electrical transport measurements ${ }^{69-71}$ and fused silica, ${ }^{72}$ indicating that these materials may grow on virtually anything.

In fact, the in-plane lattice mismatch spans a remarkable range in the context of conventional thin film growth (see Table I in Ref. 44), reaching from $0.2 \%$ for $\mathrm{Bi}_{2} \mathrm{Se}_{3}$ on $\mathrm{InP}$ all the way up to $43.8 \%$ for $\mathrm{Bi}_{2} \mathrm{Te}_{3}$ on graphene. ${ }^{44}$ The reason for this enormous tolerance of lattice mismatches lies in the layered nature of the rhombohedral crystal structure [space group $D_{3 d}^{5}(R \overline{3} \mathrm{~m})$ ] of the $(\mathrm{Bi}, \mathrm{Sb})_{2}(\mathrm{Se}, \mathrm{Te})_{3}$ compounds, which is characterized by the van der Waals (vdW) gap. Figure 1(a) illustrates a $\mathrm{Bi}_{2} \mathrm{Te}_{3}$ unit cell, in which the $\mathrm{Te}-\mathrm{Bi}-\mathrm{Te}-\mathrm{Bi}-\mathrm{Te}$ quintuple layer (QL) building blocks are illustrated, which are separated from one another by the vdW gap across which the Te-Te bonding is weak. In consequence, the bonding between the first QL and the substrate is also characterized by weak vdW forces. The vdW gap can be clearly seen in transmission electron microscopy images shown in Fig. 1(b). The vdW epitaxy growth mechanism ${ }^{74-76}$ does not require lattice matching between the film and the substrate but is nevertheless characterized by in-plane (rotational) alignment between the film and the substrate. van der Waals epitaxy has seen a renaissance with the advent of 2D materials, for which TIs provide a suitable substrate for the direct $2 \mathrm{D}$ materials growth or for integration with TIs in heterostructures for future electronic devices. ${ }^{77}$ The flip-side of the lack of strong ionic or covalent bonding across the film-substrate interface is a lack of control over the TI film growth.

The growth of $(\mathrm{Bi}, \mathrm{Sb})_{2}(\mathrm{Se}, \mathrm{Te})_{3}$ thin films by $\mathrm{MBE}$ is usually carried out with a considerable chalcogen overpressure on the order of $>5: 1$ due to the high rate of re-evaporation. The growth rate of typically less than $1 \mathrm{~nm} / \mathrm{min}$ is controlled by the group-V element flux and varies as a function of substrate temperature. The substrate temperature, which typically lies in the range between $200^{\circ} \mathrm{C}$ and $300^{\circ} \mathrm{C}$, has been shown to be the main parameter determining the quality of the films. ${ }^{44,78}$ It has proven advantageous to first grow a seed layer at a temperature of $\sim 50^{\circ} \mathrm{C}$ lower than the final growth temperature, followed by an anneal under chalcogen flux..$^{55,79}$ The growth can be monitored in situ by reflection high-energy electron diffraction (RHEED). Figure 1 (c) shows streaky RHEED patterns on $\mathrm{Bi}_{2} \mathrm{Te}_{3}$ on $c$ plane sapphire obtained along the $[11 \overline{2} 0]$ and [10 $\overline{1} 0]$ azimuths, which repeat every $60^{\circ}$. The streaky patterns are indicative of flat, crystalline surfaces and they remain intact for doped films as well, up to the critical concentration above which the streaks become diffuse (and the films rough), indicative of their non-substitutional incorporation. ${ }^{14-16}$ Note that RHEED cannot be continuously used for $(\mathrm{Bi}, \mathrm{Sb})_{2}(\mathrm{Se}, \mathrm{Te})_{3}$ growth as the electron beam visibly damages the films, most likely due to local heating. For the evaporation of $\mathrm{Bi}$ and $\mathrm{Sb}$, standard effusion cells are commonly used, whereas Se and Te are often (but not necessarily) evaporated out of special cracker cells. For the evaporation of dopants, high temperature effusion cells have proven advantageous since they are thermally better shielded, thereby reducing the unintentional evaporation of the high vapor-pressure chalcogens from surrounding areas. In fact, Se is very hard to contain and some unintentional Se "co-evaporation" is unavoidable, as shown in highresolution compositional analysis using Rutherford backscattering spectroscopy with $2.3 \mathrm{MeV} \mathrm{He}$ ions and particle-induced x-ray emission with $1 \mathrm{MeV}$ protons. ${ }^{16}$

The structural properties of the films are usually further investigated ex-situ using $\mathrm{x}$-ray diffraction $(\mathrm{XRD})$ with $\mathrm{Cu} \mathrm{K}_{\alpha 1}$ radiation. Figure 1 (d) shows the spectrum for $\mathrm{Bi}_{2} \mathrm{Te}_{3}$ film on $\mathrm{BaF}_{2}$ (111), which

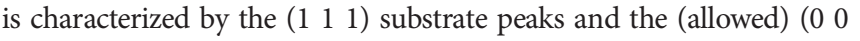
3l) film peaks, representative of $c$-axis oriented, rhombohedral single crystalline material. Upon doping, the analysis of the resulting peak shifts and peak broadening can be used to quantify the undesired degradation in crystalline quality, as well as giving clues on the doping scenario. ${ }^{18,80,81}$ Furthermore, the in-plane lattice constants, as well as the rotational symmetry of the system, can be obtained from asymmetric $2 \mathrm{D}$ reciprocal space mapping or $\varphi$-scans, as shown in Fig. 1(e). Whereas the in-plane orientation of vdW epitaxially grown films, in principle, lock to the symmetry of the underlying substrate, this locking may not be perfect. In particular $(\mathrm{Bi}, \mathrm{Sb})_{2}(\mathrm{Se}, \mathrm{Te})_{3}$ films on $c$-plane sapphire are known to exhibit rotational twins, as can be seen in the $60^{\circ}$ repeat of the streaky patterns in RHEED [cf. Fig. 1(c)] - instead of the threefold symmetry expected from the $R \overline{3} m$ crystal structure. In contrast, films grown on $\mathrm{BaF}_{2}$ (111) are twin-free, ${ }^{68}$ which alters the electronic properties of the film as well. ${ }^{82}$ Figure $1(\mathrm{e})$ shows a comparison of the threefold symmetric $\{10 \overline{1} 5\} \mathrm{Bi}_{2} \mathrm{Te}_{3}$ peaks on a smooth $\mathrm{BaF}_{2}$ surface $\left(120^{\circ}\right.$ apart) and the additional peaks due to twinning $\left(60^{\circ}\right.$ apart) on a rougher $\mathrm{BaF}_{2}$ surface (which dominates the growth on, e.g., $c$-plane sapphire).

The film morphology, and the distribution of rotational domains, can be conveniently visualized using atomic force microscopy (AFM) owing to the dominating QL-terrace structure with its $1 \mathrm{~nm}$-high steps. Figure 1(f) shows the characteristic, triangular terraced islands, which are rotated with respect to each other by $60^{\circ}$ in a $\mathrm{Bi}_{2} \mathrm{Te}_{3}$ film on $c$-plane sapphire. The triangular shape in the case of a hexagonal system can be understood in the framework of the Burton-Cabrera-Frank theory, when for particular crystallographic orientations, the distance between corners of the structure is larger than the diffusion length of the surface adatoms. ${ }^{36}$ In general, the growth is of the spiral surface growth type. ${ }^{83}$ The growth spirals are believed to be due to the pinning of $2 \mathrm{D}$ growth fronts at irregular substrate steps. ${ }^{84}$ The formation of screw dislocations in $\mathrm{Bi}_{2} \mathrm{Te}_{3}$ has been linked to variations in 
(a)

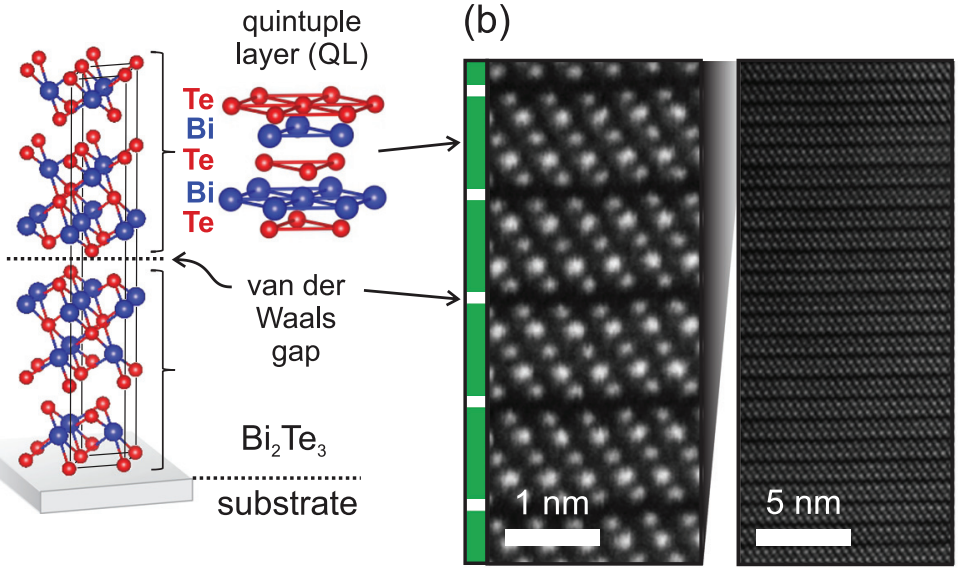

(c)
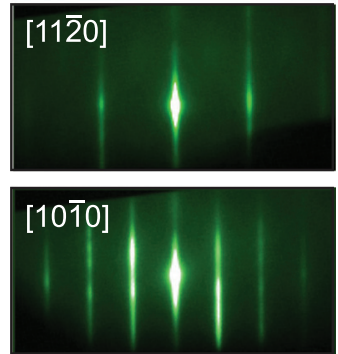

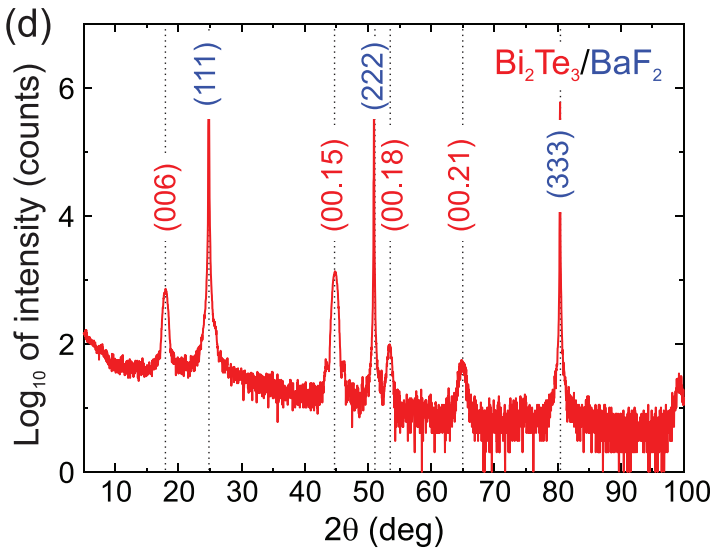

(f)

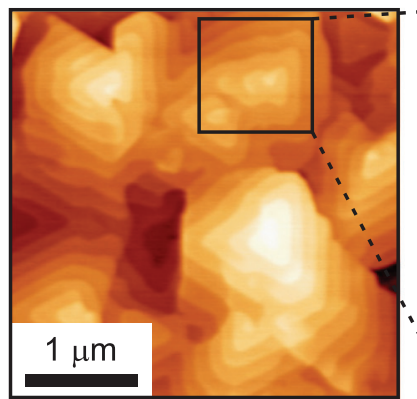

(e)

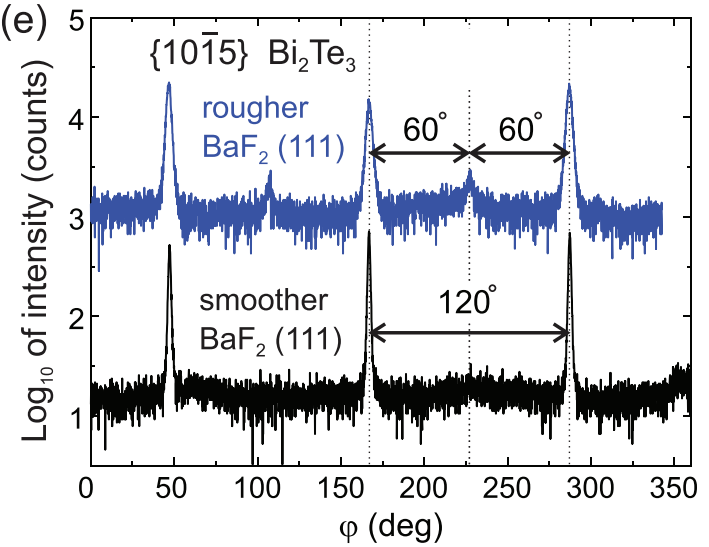

(g)

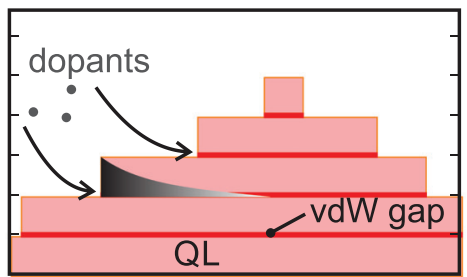

FIG. 1. Structural properties and growth of $\mathrm{Bi}_{2} \mathrm{Te}_{3}$ thin films by MBE. (a) Crystal structure. On the left, the unit cell consisting of three Te-Bi-Te-Bi-Te quintuple layer (QL) blocks is shown. The QL blocks (Bi and Te are shown in blue and red, respectively) are separated by the weakly bonding Te-Te van der Waals gap. (b) Cross-sectional highangle annular dark field scanning transmission electron microscopy. The high-resolution image on the left shows the fine structure of the QL blocks and the van der Waals gap (no intensity). The overview scan on the right shows the perfectly ordered QL stack. (c) RHEED images of $\mathrm{Bi}_{2} \mathrm{Te}_{3}$ on c-plane sapphire along the [1120] and [1010] azimuths, showing streaky patterns, indicative of flat, crystalline surfaces. (d) Out-of-plane $\theta-2 \theta$ XRD spectrum of $\mathrm{Bi}_{2} \mathrm{Te}_{3}$ on $\mathrm{BaF}_{2}$ (111). The film peaks (red) and substrate peaks (blue) are indicated. (e) In-plane XRD $\varphi$ scan of a $\{1015\} \mathrm{Bi}_{2} \mathrm{Te}_{3}$ peak. On smooth substrates (black line), only one domain is found $\left(120^{\circ}\right.$ apart), consistent with the threefold crystal symmetry. On rough substrates (blue line), two in-plane domains are found $\left(60^{\circ}\right.$ apart). (f) The surface morphology of $\mathrm{Bi}_{2} \mathrm{Te}_{3}$ on $\mathrm{c}$-plane sapphire, as obtained by AFM, is dominated by two domains of triangular islands, measuring $\sim 1 \mu \mathrm{m}$ across. On the right, the close-up reveals details of the typical 1-QL-step terrace structure as well as the spirallike growth center. (g) Schematic illustration of a $\mathrm{Bi}_{2} \mathrm{Te}_{3}$ island. The stepped structure exposes the van der Waals gap, which can act as an entry point for the efficient, but uncontrolled, diffusion of dopants into the material.

stoichiometry of the deposited nucleation centers due to Te reevaporation during the initial stages of film growth. ${ }^{36}$

This characteristic morphology of $(\mathrm{Bi}, \mathrm{Sb})_{2}(\mathrm{Se}, \mathrm{Te})_{3}$ thin films poses a major challenge for their controlled doping [see illustration in
Fig. 1(g)]. While during standard layer-by-layer growth the dopants can be incorporated in a deterministic way, allowing for the so-called $\delta$-doping of individual layers, ${ }^{85,86}$ the exposed vdW gap of the terraced islands with its relatively weak electrostatic bonding forces and large 
layer spacings provides an entry portal for the uncontrolled incorporation of dopants. ${ }^{87}$ This is particularly concerning since the diffusion constants in these layered hosts are highly anisotropic, with the diffusion along the planes (in the vdW gap) being particularly fast. ${ }^{87-89}$ The diffusing dopants are then incorporated into the $(\mathrm{Bi}, \mathrm{Sb})_{2}(\mathrm{Se}, \mathrm{Te})_{3}$ host, illustrated by the concentration gradient in Fig. 1(g), as the solubility limit for interstitial metal incorporation is usually low. This is certainly no surprise and a long-standing problem ${ }^{87}$ in the thermoelectrics community where the electric contacting with the obvious choices of low electrical resistivity and high thermal conductivity metals has been challenging (with a few exceptions such as $\mathrm{Ta}^{90}$ ) mostly resulting in the degeneration (or even complete dissolution $^{91}$ ) of the electrodes in the case of, e.g., $\mathrm{Sn},{ }^{92} \mathrm{Ag},{ }^{93}$ and $\mathrm{Au} .{ }^{91}$ For instance, $\mathrm{Cu}$ is notorious for its high diffusivity in $\mathrm{Bi}_{2} \mathrm{Te}_{3}$ of $10^{-6} \mathrm{~cm}^{2} \mathrm{~s}^{-1}$ parallel to the plane and $3 \times 10^{-15} \mathrm{~cm}^{2} \mathrm{~s}^{-1}$ along the $c$-axis at room temperature ${ }^{87}$ and the formation of binary chalcogenides. For electrodes, specific diffusion barriers have been developed (e.g., Ni barriers for Sn electrodes); however, some of them rely on the formation of secondary chalcogen compounds at the interface $^{92}$ and so do not provide a solution for achieving controlled, substitutional doping of TIs.

The need to break TRS in TIs led to a very active quest for suitable dopants to introduce magnetic order. Magnetic TIs (MTIs) were achieved with magnetic dopants, both with transition metals (TMs) and rare earths (REs).

With TMs, magnetic order has been observed in Fe-, Mn-, Cr-, and V-doped compounds. For Fe-doping in $\mathrm{Sb}_{2} \mathrm{Te}_{3}$ and $\mathrm{Bi}_{2} \mathrm{Se}_{3}$, the compounds remained paramagnetic while the electron concentration was increased, despite successful substitutional doping ${ }^{94,95}$ and $p d-$ hybridization predicted by spin density calculations. ${ }^{96}$ In contrast, Kulbachinskii et al. reported ferromagnetic (FM) ordering up to $12 \mathrm{~K}$ in $(\mathrm{Fe}, \mathrm{Bi})_{2} \mathrm{Se}_{3}$ single crystals. ${ }^{97}$

In Mn-doped Tis, FM order has been observed in bulk crystals and thin films. In addition, there are reports on the surface magnetism in $\mathrm{Mn}: \mathrm{Bi}_{2} \mathrm{Se}_{3}$ with observations of both an enhanced moment and $T_{\mathrm{C}}$ due to surface segregation of the $\mathrm{Mn}$ ions, ${ }^{98}$ as well as a diminished surface moment and soft magnetic behavior with no hysteresis possibly caused by partial antiferromagnetic (AF) ordering near the surface. ${ }^{18} \mathrm{~A}$ bandgap has been observed in Mn-doped TIs, but it is likely not of magnetic origin..$^{99}$

Of all the single-ion dopants tried so far, $\mathrm{Cr}$ and $\mathrm{V}$ possess the most robust long-range FM order with out-of-plane anisotropy and a typical (doping concentration-dependent) $T_{\mathrm{C}}$ of $59 \mathrm{~K}(104 \mathrm{~K})$ for $\mathrm{Cr}(\mathrm{V})$ concentrations of $x=0.29(0.25)$ in $\mathrm{Sb}_{2-x}(\mathrm{~V} / \mathrm{Cr})_{x} \mathrm{Te}_{3}{ }^{23}$ In Table I, we summarize the properties of the most common TI dopants.

TABLE I. Summary of the physical properties of transition metal and rare earth element doped TI thin films. The doping concentration is given in $\%$ of the (Bi+Sb) sites for substitutional (SUB) doping, unless otherwise noted [e.g., for interstitial (INT) doping]. The magnetic moment is given per doping ion (in $\mu_{\mathrm{B}}$ ) and the transition temperature (trans. temp. $T_{\mathrm{C}}$ or $T_{\mathrm{N}}$ in $\mathrm{K}$ ). The out-of-plane (OOP) magnetocrystalline anisotropy (MCA) is indicated when stated in the reference.

\begin{tabular}{|c|c|c|c|c|c|c|c|c|c|c|}
\hline Dopant & TI host & $\begin{array}{c}\text { Doping } \\
\text { conc. (at.\%) }\end{array}$ & Valence & $\begin{array}{c}\text { Magnetic } \\
\text { moment } \\
\left(\mu_{\mathrm{B}}\right)\end{array}$ & $\begin{array}{l}\text { Magnetic } \\
\text { order }\end{array}$ & $\begin{array}{l}\text { Trans. } \\
\text { temp. }(\mathrm{K})\end{array}$ & MCA & $\begin{array}{l}\text { Open } \\
\text { loop }\end{array}$ & Comments & References \\
\hline $\mathrm{Cr}$ & $\mathrm{Bi}_{2} \mathrm{Se}_{3}$ & $\leq 5.2^{*}$ & $<3+$ & $2^{\dagger}$ & FM & $20^{\ddagger}$ & $\ldots$ & Yes & $\begin{array}{l}{ }^{*} \text { Poor cryst. quality for }>5 \% \mathrm{Mn} \\
{ }^{\dagger} \text { Max. for } 2 \% \mathrm{Mn} \text {; }{ }^{\ddagger} \text { max. for } 5.2 \% \mathrm{Mn}\end{array}$ & 80 \\
\hline $\mathrm{Cr}$ & $\mathrm{Bi}_{2} \mathrm{Se}_{3}$ & 12 & $2+$ & $\sim 2.1$ & FM & $\ldots$ & OOP & Yes & SUB and INT & 18 \\
\hline $\mathrm{Cr}$ & $\mathrm{Bi}_{2} \mathrm{Se}_{3}$ & $0.6^{\dagger}$ & $\begin{array}{l}\text { Mixed } \\
2+, 3+\end{array}$ & $\begin{array}{c}2.49^{*} \\
1.3^{*}\end{array}$ & FM & $\begin{array}{l}46^{*} \\
31^{\ddagger}\end{array}$ & OOP & & $\begin{array}{l}{ }^{\dagger} \text { Effective conc. for modulation doping } \\
{ }^{*} \text { Surface value; }{ }^{\ddagger} \text { bulk value }\end{array}$ & 104 \\
\hline $\mathrm{Cr}$ & $\mathrm{Sb}_{2} \mathrm{Te}_{3}$ & $7.5-21$ & $2+$ & 2.8 & FM & $28-125$ & OOP & Yes & SUB & 105 \\
\hline $\mathrm{Cr}$ & $(\mathrm{Bi}, \mathrm{Sb})_{2} \mathrm{Te}_{3}$ & 5 & $<3+$ & 3.19 & FM & 20 & OOP & Yes & Zener-type $p d$-exchange interaction & 106 \\
\hline $\mathrm{Cr}$ & $(\mathrm{Bi}, \mathrm{Sb})_{2} \mathrm{Te}_{3}$ & $\leq 15$ & $3+$ & 2.9 & FM & $\leq 59^{*}$ & OOP & Yes & ${ }^{*} 14-59 \mathrm{~K}$ for $5-15 \% \mathrm{Cr}$ & 23 \\
\hline $\mathrm{V}$ & $\mathrm{Bi}_{2} \mathrm{Se}_{3}$ & $\leq 12$ & $\ldots$ & $\ldots$ & FM & $\leq 16^{*}$ & OOP & Yes & ${ }^{*} 10 \mathrm{~K}$ for $1 \%, 16 \mathrm{~K}$ for $6 \%$ & 107 \\
\hline $\mathrm{V}$ & $(\mathrm{Bi}, \mathrm{Sb})_{2} \mathrm{Te}_{3}$ & $\leq 13$ & $\begin{array}{c}\text { Mixed } \\
3+, 4+\end{array}$ & 1.5 & FM & $\leq 104^{*}$ & OOP & Yes & $\begin{array}{c}{ }^{*} 23-104 \mathrm{~K} \text { for } 4-13 \% \mathrm{~V} \\
\text { SUB }\end{array}$ & 23 \\
\hline V & $\mathrm{Sb}_{2} \mathrm{Te}_{3}$ & 5 & $<3+$ & 1.84 & FM & 45 & OOP & Yes & Zener-type $p d$-exchange interaction & 106 \\
\hline $\mathrm{Mn}$ & $\mathrm{Bi}_{2} \mathrm{Te}_{3}$ & $\leq 10$ & $\ldots$ & $\ldots$ & $\mathrm{FM}^{*}$ & $\leq 17$ & OOP & Yes & SUB and INT possible; $\mathrm{FM}^{*}: \geq 2 \% \mathrm{Mn}$ & 108 \\
\hline $\mathrm{Mn}$ & $\mathrm{Bi}_{2} \mathrm{Se}_{3}$ & $\ldots$ & $\begin{array}{c}\text { mostly } \\
2+\end{array}$ & $\begin{array}{l}1.6^{*} \\
5.1^{\dagger}\end{array}$ & FM & 1.5 & OOP & No & $\begin{array}{c}\text { XAS: }{ }^{109} \text { SUB and INT } \\
{ }^{*} \mathrm{XMCD}^{\dagger} \text { SQUID }\end{array}$ & 19 \\
\hline $\mathrm{Mn}$ & $\mathrm{Bi}_{2} \mathrm{Te}_{3}$ & $\leq 13$ & $\ldots$ & $\ldots$ & $\mathrm{FM}^{*}$ & $\leq 15$ & OOP & Yes & $\begin{array}{c}\text { vdW gap INT } \\
{ }^{*} \mathrm{FM} \geq 3 \% \mathrm{Mn} ; \max T_{\mathrm{C}} \text { for } 9 \%\end{array}$ & 110 \\
\hline Gd & $\mathrm{Bi}_{2} \mathrm{Te}_{3}$ & $\leq 30$ & $3+$ & 7 & AFM & -2.5 & $\ldots$ & No & XAS: ${ }^{111}$ SUB & 14,112 \\
\hline Dy & $\mathrm{Bi}_{2} \mathrm{Te}_{3}$ & $\leq 36$ & $3+$ & $4.3-12.6$ & AFM & -1.2 & $\ldots$ & No & XAS: ${ }^{111}$ SUB & 15 \\
\hline Ho & $\mathrm{Bi}_{2} \mathrm{Te}_{3}$ & $\leq 21$ & $3+$ & 5.15 & AFM & -0.837 & $\ldots$ & No & XAS: ${ }^{111}$ SUB & 16 \\
\hline $\mathrm{Eu}$ & $\mathrm{Bi}_{2} \mathrm{Te}_{3}$ & $\leq 4$ & $2+$ & $\cdots$ & $\ldots$ & $\cdots$ & $\cdots$ & $\cdots$ & SUB, EuTe for $9 \% \mathrm{Eu}$ & 113 \\
\hline $\mathrm{Eu}$ & $\mathrm{Bi}_{2} \mathrm{Se}_{3}$ & $\leq 21$ & $\ldots$ & $\ldots$ & FM & $8-64$ & $\ldots$ & Yes & Nonuniform Eu SUB; FM $\geq 10 \% \mathrm{Eu}$ & 114 \\
\hline
\end{tabular}


In line with these findings, the QAHE has been observed in both $\mathrm{Cr}$ - and V-doped samples but not in Mn or Fe doped ones (except for the intrinsic magnetic TIs based on $\left.\mathrm{MnBi}_{2} \mathrm{Te}_{4}\right) \cdot{ }^{21,100}$ However, the fact that even in these materials the QAHE is limited to very low temperatures, far below $T_{\mathrm{C}}$, calls the nature and robustness of the magnetic order into question.

Early theoretical and experimental studies ${ }^{7,115,116}$ on Cr- and Vdoped TIs proposed that long-range magnetic ordering of the Van Vleck type could be established. ${ }^{117}$ This type of magnetic order is stabilized by intra-atomic mixing of the $d$-orbital ground state with higher energy excitations close in energy, which lead to a positive exchange integral. Observations of long-range magnetic order in Crand V-doped thin films and crystals were first investigated by superconducting quantum interference device (SQUID) magnetometry, $\mathrm{x}$-ray magnetic circular dichroism (XMCD), and polarized neutron reflectometry (PNR), ${ }^{18,80,105,106}$ which reported a clear ferromagnetic transition and open hysteresis loops with out-of-plane anisotropy and, crucially, a doping concentration-dependent $T_{\mathrm{C}}$. This is incompatible with the notion of magnetic order dominated by intra-atomic interactions and, instead, strongly hints at a magnetic ordering mechanism that is dependent on either carrier or spin concentrations.

The exact features of the magnetic ordering appear to depend on the details of the modification of the electronic band structure due to the dopant. For instance, in V-doped samples, impurity bands caused by the $\mathrm{V} 3 d$ states are found near the Fermi energy, $E_{\mathrm{F}}$, and Dirac point of the system. ${ }^{118,119}$ These states appear to stabilize the magnetic ordering. Both $\mathrm{V}$ and $\mathrm{Cr}$ show significant $p d$ hybridization between the host $5 p$ states and the dopant $3 d$ states in $\mathrm{Sb}_{2} \mathrm{Te}_{3}$ based compounds as has been observed by a number of groups using $\mathrm{XMCD}^{20,101,118,120}$ Figure 2(a) shows the XMCD signal due to induced spin polarization in the $\mathrm{Sb} p$-states for a $\mathrm{Cr}$-doped $\mathrm{Sb}_{2} \mathrm{Te}_{3}$ thin film. As the conduction and valence bands are mainly formed by the host lattice $p$-states, this leads to the question if it is not the carriers that mediate magnetic order in these systems. In the tetradymite dichalcogenides, near the center of the Brillouin zone, the valence band is formed by the anion $p$-states of Te or Se, whereas the conduction band is formed by the $p$-states of the $\mathrm{Sb}$ and $\mathrm{Bi}$ cations, though it has recently been shown that the bonds of magnetically doped compounds have a strong covalent character. ${ }^{106}$

The important role carriers play in stabilizing the magnetic order was shown by the gate-voltage dependence of the magnetic relaxation time ${ }^{103}$ and strongly supported by the dependence of $T_{\mathrm{C}}$ on the concentration of $\mathrm{Bi}$, acting as a counter dopant, in $\mathrm{V}$ - and Cr-doped films. Ye et al. showed, by systematically varying the dopant and Bi concentration in $\mathrm{Cr}$ : $(\mathrm{Sb}, \mathrm{Bi}){ }_{2} \mathrm{Te}_{3}$ and $\mathrm{V}$ : $(\mathrm{Sb}, \mathrm{Bi})_{2} \mathrm{Te}_{3}$, not only that the magnetic ordering is stabilized with the increasing doping concentration but also that $T_{\mathrm{C}}$ is systematically suppressed when the carrier-hole concentration is decreased by substituting $\mathrm{Sb}$ with $\mathrm{Bi}^{101,120}$ Figure 2(b) shows Arrott plots from which the values of $T_{\mathrm{C}}$ are determined for systematically varied $\mathrm{Cr}$ and $\mathrm{Bi}$ concentrations in $\mathrm{Cr}_{x}\left(\mathrm{Sb}_{1-y} \mathrm{Bi}_{y}\right)_{2-\mathrm{x}} \mathrm{Te}_{3}$ crystals. An increase in the $\mathrm{Cr}$ concentration stabilizes the magnetic order, whereas an increase in Bi strongly suppresses it. First principles calculations show the extent of the magnetic coupling in the $c$-axis direction across the vdW gap. The picture that emerges is that of a dominant carrier-mediated interaction based on the hybridization of the $d$-states of the dopants with the carrier bands formed by the $p$-states of the host lattice, similar to the ordering in dilute magnetic semiconductors. ${ }^{121,122}$ In addition, it seems that the introduction of Bi weakens the $p d$-hybridization between the $5 p$ states and the $3 d$ states. ${ }^{101}$ Apart from this carrier-mediated exchange, there is evidence of exchange interactions mediated by the host ions. ${ }^{118,119}$ Notwithstanding, it is clear that the necessary tuning to reduce unwanted bulk carriers will always be detrimental to the long-range magnetic order in these compounds.

It seems that the surface magnetism can differ from the bulk behavior, in particular, in Cr-based compounds. For instance, in Ref. 123 , it was shown that the surface magnetization lies in-plane, rather than following the bulk out-of-plane anisotropy. However, the study by Ye et al. using surface-sensitive XMCD in total-electron yield mode on $\mathrm{Cr}$-doped $(\mathrm{Sb}, \mathrm{Bi})_{2} \mathrm{Te}_{3}$ did not find any evidence for a variation of the Cr-magnetism at the surface, neither did Duffy et al. ${ }^{20}$ In the work by Liu et al., ${ }^{104}$ it was reported that $T_{\mathrm{C}}$ for modulation-doped $\mathrm{Bi}_{2} \mathrm{Te}_{3}$ increased if the $\mathrm{Cr}$ dopants were introduced at the sample surface.

Using muon spin rotation $\left(\mu^{+} \mathrm{SR}\right)$ techniques, the magnetic volume fraction can be directly tracked as a function of temperature in Cr- and V-doped thin films of $\mathrm{Sb}_{2} \mathrm{Te}_{3}$ and other TIs. ${ }^{102,124}$ These measurements show that ferromagnetic ordering develops rather gradually over a wide temperature range and that for lower doping concentrations, a significant fraction of the material remains paramagnetic. The magnetic transition can also be tracked through the slow relaxation rate during the phase transition in $\mu \mathrm{SR}$ measurements [see Fig. 2(c)]. This relaxation rate is a measure of the static and $\mu \mathrm{s}$-dynamic magnetic disorder in the system. This peak is very broad, and, for lower doping concentrations, disorder persists down to at least $4 \mathrm{~K}$, the lowest temperature reachable in the system.

Furthermore, a change of the internal magnetic field experienced by the muons in the samples provides evidence for a percolation transition, above which magnetically ordered clusters gradually appear in a paramagnetic sea, growing and percolating as the temperature is decreased. ${ }^{102}$ For lower doping concentrations, the internal field remains shifted even at the lowest temperatures. ${ }^{102,124}$ This behavior is likely due to residual paramagnetic regions, which remain between the ferromagnetic patches. Note that there can also be a large difference in percolation between surface and bulk due to different screening behaviors. ${ }^{125}$ Lachman et al. ${ }^{103}$ investigated the magnetic domain pattern in a Cr-doped $(\mathrm{Sb}, \mathrm{Bi})_{2} \mathrm{Te}_{3}$ film using scanning SQUID-on-tip microscopy [see Fig. 2(d)]. In their measurements, the nearly non-interacting, slowly fluctuating, superparamagnetic domains were directly imaged. These measurements show directly that the magnetic order in TM-doped TIs is not robust over long lengthscales. Instead, a picture of superparamagnetic or superferromagnetic domains emerges, which gradually form during a broad transition, and with significant disorder, and paramagnetic regions remaining intact until far below $T_{\mathrm{C}}$ [see illustration in Fig. 2(e)]. With an increase in doping concentration, the distances between the dopant ions shrink and additional carriers are introduced into the system. The net effect is the stabilization of the magnetic order, but at the cost of severely compromising the quantum properties of the material.

The phenomenon of nanoscale magnetic phase separation is known from dilute magnetic semiconductors, such as GaMnAs. There, depending on the extent of the localization of the (hole) carriers, either the magnetic transition follows the percolation dynamics of bound magnetic polarons in the case of strongly localized holes ${ }^{126}$ 

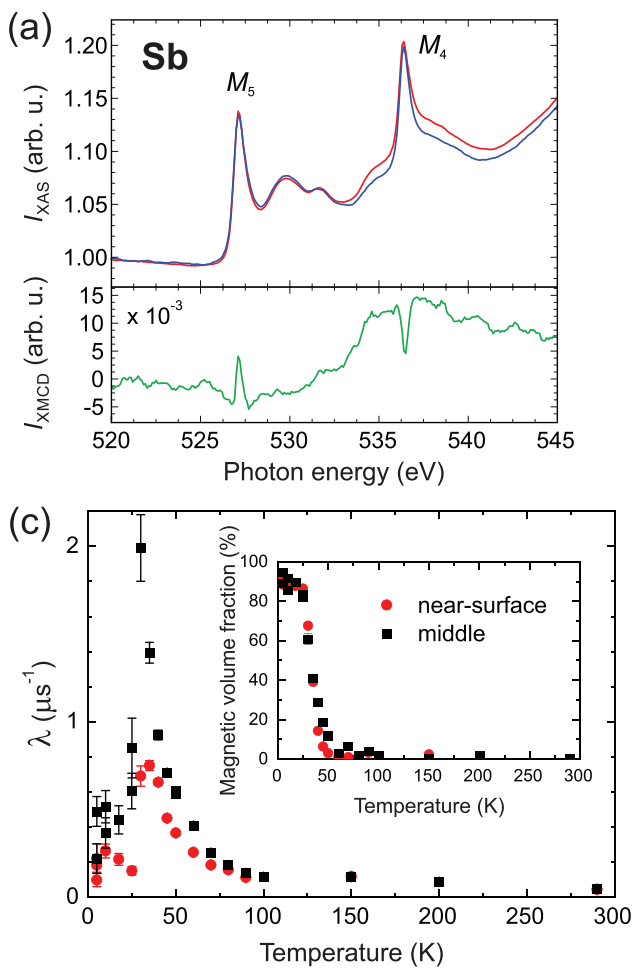

(e)

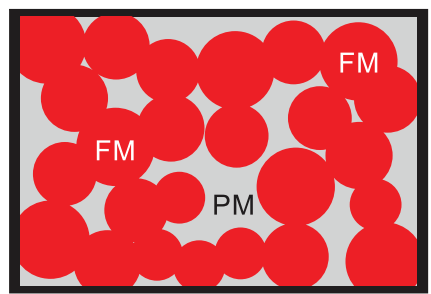

(b)

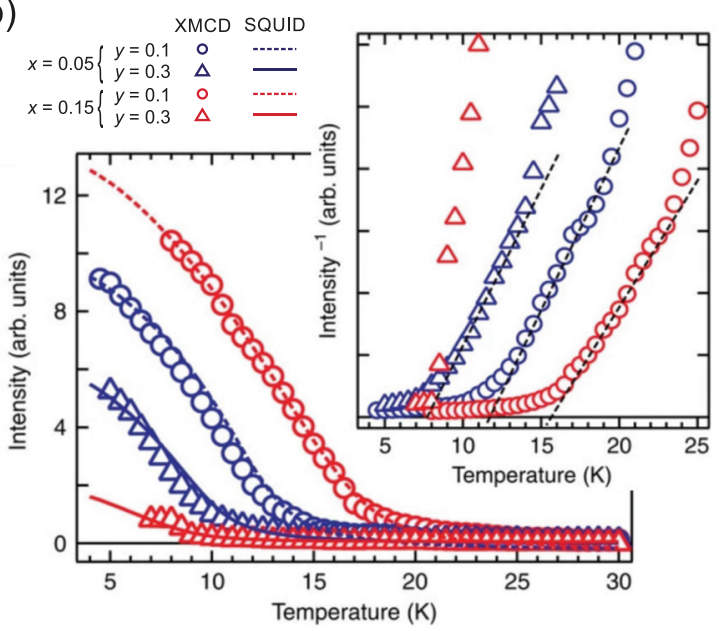

(d)

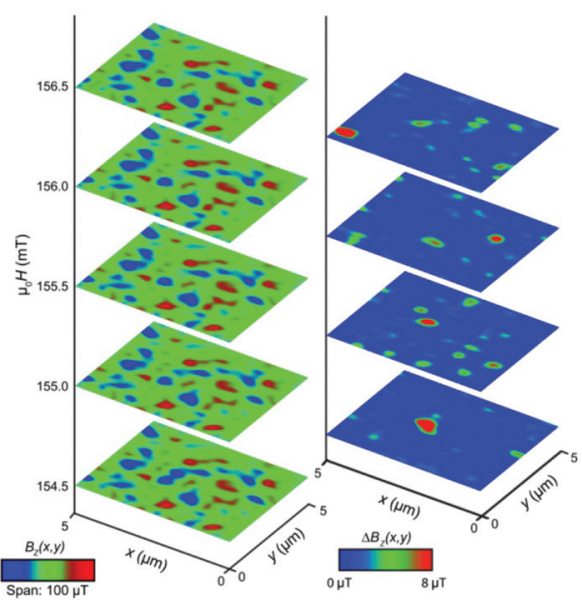

FIG. 2. Magnetic properties of MTI films. (a) X-ray absorption (XAS) and x-ray magnetic circular dichroism (XMCD) spectra at the Sb $M_{4,5}$ edges of an in situ cleaved $\mathrm{Cr}_{\mathrm{Bi}} \mathrm{Te}_{3}$ film. The measurement was carried out in a field of $8 \mathrm{~T}$ and at a temperature of $3 \mathrm{~K}$. The XMCD signal (green) is obtained by subtracting the XAS spectrum measured with right-circularly polarized $x$-rays (blue) from the one measured with left-circularly polarized x-rays (red). ${ }^{20}$ (b) XMCD intensities (symbols) and SQUID magnetization data (lines) obtained for different $\mathrm{Cr}$ doping concentrations $x$ and different $\mathrm{Sb}$ to Bi ratios in counter-doped $\mathrm{Cr}_{x}\left(\mathrm{Sb}_{1-y} \mathrm{Bi}_{y}\right)_{2-x} \mathrm{Te}_{3}$ crystals. ${ }^{101}$ From the plot of the inverse intensity (i.e., magnetization) in the panel on the right, the transition temperature is estimated, which shows a clear trend: $T_{\mathrm{C}}$ increases with $x$, whereas an increase in Bi:Sb ratio strongly reduces it. (c) Temperature-dependent transverse-field $\mu^{+} \mathrm{SR}$ measurement showing the magnetic transition in a $\mathrm{Cr}_{\mathrm{Sb}} \mathrm{Se}_{3}$ film. ${ }^{102}$ The data shown in red represent the behavior of the near-surface region of the film, whereas the (higher muon energy) data shown in black include the information from the middle of the film as well. The relaxation rate $\lambda$, which is a measure of the static and dynamic $(\mu \mathrm{s})$ magnetic disorder in the system, is very broad across the magnetic transition. (d) SQUID-on-tip microscopy showing the magnetization reversal dynamics of a $\mathrm{Cr}$ :(Bi,Sb) ${ }_{2} \mathrm{Te}_{3}$ film. (Left) magnetic images, i.e., the $B_{z}$ component of the film magnetization, obtained in applied magnetic fields increasing $\left(0.5 \mathrm{mT}\right.$ field steps) at a temperature of $250 \mathrm{mK}$. (Right) change in the film's magnetic flux, illustrating the reversal of isolated domains. ${ }^{103}$ (e) lllustration of the magnetic order in TM-doped Tls, showing magnetically ordered and paramagnetic regions coexisting at temperatures far below $T_{\mathrm{C}}$. Panel (a) adapted from Duffy et al., Phys. Rev. B 95, 224422 (2017). Copyright 2017 Authors, licensed under a Creative Commons Attribution CC BY 4.0 license. Panel (b) reproduced with permission from Ye et al., Nat. Commun. 6, 8913 (2015). Copyright 2015 Authors, licensed under a Creative Commons Attribution CC BY 4.0. license Panel (d) adapted from Lachman et al., Sci. Adv. 1, e1500740 (2015). Copyright 2015 Authors, licensed under a Creative Commons Attribution CC BY 4.0 license.

or, in the case of hole states extended over distances longer than the average dopant distance, the Zener model becomes valid. ${ }^{121}$ However, even in the Zener model description, paramagnetic regions may persist below $T_{\mathrm{C}}$ in hole-free regions. ${ }^{122}$

Rare earth dopants are extremely attractive given their large, localized magnetic moments and their similarity to the Bi and Sb ions in the host lattice. The ionic radius of $\mathrm{Dy}^{3+}$ is $105 \mathrm{pm}$, much more similar to that of $\mathrm{Bi}^{3+}(117 \mathrm{pm})$ than to $\mathrm{Cr}^{2+}$ in the high (low) spin state of 94 (87) pm. Doping with a high moment ion has the advantage that as the exchange gap is dependent on the size of the magnetization, the doping concentration can be reduced for the same gap size, thereby preserving crystal quality. Of the rare earth lanthanide series, the high moment materials Gd, Dy, and Ho were all used to dope $\mathrm{Bi}_{2} \mathrm{Te}_{3}{ }^{14-16}$ However, none of these materials display long-range magnetic order by themselves. ${ }^{14-17,127}$ Doping concentrations of up to $35 \%$ were achieved in Gd-doped $\mathrm{Bi}_{2} \mathrm{Te}_{3}$ thin films; much above the bulk 
solubility limit. ${ }^{81}$ The details of the magnetic configurations are given in Table I. Of the investigated RE dopants, Dy shows the most interesting properties: it is the only ion that leads to a concentrationdependent moment, its susceptibility is large, and thin films can be magnetically saturated in fields as low as $\sim 2 \mathrm{~T}$. PNR measurements have shown that the induced moment can be as large as $\sim 1 / 3$ of the full $\mathrm{Dy}^{3+}$ moment at fields as low as $0.65 \mathrm{~T} .^{128} \mu^{+}$SR measurements showed that while no long-range order can be established, strong, short-range magnetic correlations establish themselves with decreasing temperature. ${ }^{128}$ This makes Dy-doped TIs a prime candidate for further exploitation in heterostructures, where order can be introduced via proximity coupling. ${ }^{129,130}$

Incorporating TIs into magnetic heterostructures has been explored both as an alternative to magnetic doping and as an added materials design opportunity to tune the magnetic properties. Magnetic heterostructures offer the advantage of, e.g., opening an exchange gap in the TI with less disorder than in doped systems since no extra scattering centers need to be introduced. It is proposed that when a non-magnetic TI is combined with another magnetically ordered material, proximity effects at the interface involving the surface Dirac fermions will align spin moments of the TI band with the itinerant carriers and give rise to exchange splitting. Similar exchange mechanisms are used in stacks with MTIs to alter their magnetic properties. Engineering heterostructures by incorporating magnetic and non-magnetic TIs has therefore opened up new avenues to access emergent quantum phenomena. In the following, we review some of these aspects of magnetic heterostructures incorporating TIs.

Several strategies have been followed in order to exploit magnetic proximity effects at the interface of such heterostructures with the goal of tuning and controlling the magnetic and quantum transport properties of MTIs. Modulation doping in heterostructures with Cr-doped $(\mathrm{Bi}, \mathrm{Sb})_{2} \mathrm{Te}_{3}$ films has increased the QAHE temperature from $\sim 30 \mathrm{mK}$ up to $2 \mathrm{~K}^{131}$ The designed structures are illustrated in Figs. 3(a) and 3(b), and the characteristic magnetotransport data showing the QAHE are plotted in Fig. 3(c). This approach has also allowed for the observation of the axion insulator state in MTIs ${ }^{132}$ - a magnetoelectric phenomenon characterized by a large longitudinal resistance and zero Hall plateau (where both the Hall and longitudinal conductivity become zero), which is illustrated in Fig. 3(d).

In order to raise the temperature at which quantum and magnetoelectric effects in MTIs can be observed, it seems natural to explore ways to increase their magnetic ordering temperature by, e.g., interfacial magnetic interactions. Growth of $\mathrm{Cr}$-doped $\mathrm{Bi}_{2} \mathrm{Se}_{3}$ films onto the high $T_{\mathrm{C}}$ $(\sim 550 \mathrm{~K})$ ferrimagnetic insulator $\mathrm{Y}_{3} \mathrm{Fe}_{5} \mathrm{O}_{12}$ (YIG) was found to enhance the $T_{\mathrm{C}}$ of the MTI from $\sim 20 \mathrm{~K}$ up to $\sim 50 \mathrm{~K}$. ${ }^{133}$ The evaporation of a thin FM layer, such as Fe or Co, onto the pristine surface of in-vacuum cleaved Mn-doped $\mathrm{Bi}_{2} \mathrm{Te}_{3}$ crystals or Cr-doped $\mathrm{Bi}_{2} \mathrm{Se}_{3}$, Cr-doped $\mathrm{Sb}_{2} \mathrm{Te}_{3}$, and Dydoped $\mathrm{Bi}_{2} \mathrm{Te}_{3}$ thin films was also demonstrated to alter their $T_{\mathrm{C}}$ near the surface of the TI through proximity. ${ }^{20,127,134,135}$ Figures 3(e) and 3(f) depict the increase in $T_{\mathrm{C}}$ for $\mathrm{Cr}$-doped $\mathrm{Bi}_{2} \mathrm{Se}_{3}$ and $\mathrm{Sb}_{2} \mathrm{Te}_{3}$ films with a Co overlayer, as obtained from XMCD measurements. Growth of high-quality $\mathrm{Dy}: \mathrm{Bi}_{2} \mathrm{Te}_{3} / \mathrm{Cr} \mathrm{Sb}_{2} \mathrm{Te}_{3}$ heterostructures resulted in successful introduction of long-range magnetic order in $\mathrm{Dy}_{\mathrm{Bi}} \mathrm{Bi}_{2} \mathrm{Te}_{3}$ as a result of proximity coupling to the higher transition temperature $\mathrm{Cr}_{\mathrm{Sb}} \mathrm{Te}_{2}$ layer. $^{129}$

Alternative approaches to raise $T_{\mathrm{C}}$ of MTIs include their coupling to antiferromagnets. An example is superlattices of the $\mathrm{AF} \mathrm{CrSb}$ and $\mathrm{Cr}$-doped $(\mathrm{Bi}, \mathrm{Sb})_{2} \mathrm{Te}_{3}$, where $T_{\mathrm{C}}$ was found to increase from $\sim 38 \mathrm{~K}$ up to $\sim 90 \mathrm{~K}^{136,137}$ The successful design of such structures relies on the fact that these materials are chemically very compatible and well lattice-matched, resulting in abrupt interfaces which support the magnetic exchange across the interface. This concept of using materials with related or at least comparable crystal structure and similar atomic compositions has also been explored, both theoretically and experimentally, in heterostructures of $\mathrm{MnBi}_{2} \mathrm{Te}_{4} / \mathrm{Bi}_{2} \mathrm{Te}_{3}, \mathrm{MnBi}_{2} \mathrm{Se}_{4} /$ $\mathrm{Bi}_{2} \mathrm{Se}_{3}, \mathrm{MnSe} / \mathrm{Bi}_{2} \mathrm{Se}_{3}$, and similar compounds. ${ }^{138-141}$ In particular, heterostructures of, e.g., $\mathrm{MnBi}_{2} \mathrm{Te}_{4}$ and $\mathrm{Bi}_{2} \mathrm{Te}_{3}$, which are part of the $\left(\mathrm{MnBi}_{2} \mathrm{Te}_{4}\right)\left(\mathrm{Bi}_{2} \mathrm{Te}_{3}\right)_{m}$ homologous series, ${ }^{142}$ are particularly suited as there are no real interfaces (the $\mathrm{MnBi}_{2} \mathrm{Te}_{4}$ layer is effectively terminated by $\mathrm{Bi}_{2} \mathrm{Te}_{3}$ layers). This makes the magnetic film a natural extension of the TI and allows for efficient TRS breaking. In fact, some of these systems exhibit ferromagnetism up to room temperature and a clear Dirac cone gap opening of $\sim 100 \mathrm{meV}$. $^{140}$

The latter examples have an additional advantage in terms of the electrical characteristic of the magnetic layer. They use magnetic insulators (MIs), instead of metallic films, which preserve the band structure of the TI, and thus the TSS, as they avoid hybridization with the bulk states of the AF or FM in contact. Using a MI is also convenient for the fabrication and incorporation of such structures into quantum devices. Intensive investigation of proximity effects has been done in heterostructures comprising TIs and MIs, such as $\mathrm{EuS} / \mathrm{Bi}_{2} \mathrm{Se}_{3}$, EuS/ $(\mathrm{Bi}, \mathrm{Sb})_{2} \mathrm{Te}_{3}, \quad(\mathrm{Bi}, \mathrm{Sb})_{2} \mathrm{Te}_{3} / \mathrm{Y}_{3} \mathrm{Fe}_{5} \mathrm{O}_{12}, \quad(\mathrm{Bi}, \mathrm{Sb})_{2} \mathrm{Te}_{3} / \mathrm{Tm}_{3} \mathrm{Fe}_{5} \mathrm{O}_{12}, \mathrm{Bi}_{2} \mathrm{Te}_{3} /$ $\mathrm{Fe}_{3} \mathrm{O}_{4}, \quad(\mathrm{Bi}, \mathrm{Sb})_{2} \mathrm{Te}_{3} / \mathrm{Cr}_{2} \mathrm{Ge}_{2} \mathrm{Te}_{6}$, and (Zn,Cr)Te/(Bi,Sb) ${ }_{2} \mathrm{Te}_{3} /$ $(\mathrm{Zn}, \mathrm{Cr}) \mathrm{Te}{ }^{124,143-151}$ However, the QAHE has only been reported in $(\mathrm{Zn}, \mathrm{Cr}) \mathrm{Te} /(\mathrm{Bi}, \mathrm{Sb})_{2} \mathrm{Te}_{3} /(\mathrm{Zn}, \mathrm{Cr}) \mathrm{Te},{ }^{150}$ which results from the appropriate design of the heterostructure to guarantee smooth interfaces (as it satisfies the conditions described above), as well as the maximization of the exchange gap at the top and bottom surface states by using a MI/TI/MI sandwich stack.

Proximity effects due to exchange interactions are not the only interesting phenomena that emerge at TI interfaces. The helical locking of the TSS, illustrated in Fig. 3(g), and the strong spin-orbit coupling are very relevant for their application in topological spintronics. The existence of such a spin texture means that an electron current flowing on the surface of a TI can generate a non-equilibrium spin density [see Fig. 3(h)] with both in-plane and out-of-plane components. The spinpolarized surface currents are expected to efficiently induce out-of-plane and in-plane torques in an adjacent magnetic layer. Experiments of spinpumping using ferromagnetic resonance (FMR) techniques in FM/TI and FM/TI/FM stacks, as the one depicted in Fig. 3(i), have confirmed the ability of a TI to absorb and transfer a pure spin current. ${ }^{152-156}$ Figure 3(j) shows signatures of transfer of angular momentum between the FMs $\mathrm{Co}_{50} \mathrm{Fe}_{50}$ and $\mathrm{Ni}_{81} \mathrm{Fe}_{19}$ (Py, Permalloy), mediated by $\mathrm{Bi}_{2} \mathrm{Se}_{3}$, as observed in the amplitude and phase of precession of each FM layer recorded in time-resolved FMR measurements. ${ }^{153,155}$

The absence of bulk conduction in ideal TIs further increases their spin-charge conversion efficiency. Exceptionally large spincharge conversion values at TI/FM interfaces have been experimentally demonstrated by spin-orbit torque (SOT) measurements. ${ }^{157-161}$ Figure 3(k) shows a diagram of a $\mathrm{Py} / \mathrm{Bi}_{2} \mathrm{Se}_{3}$ bilayer, where the nonequilibrium magnetization produced by an in-plane charge current in SOT measurements is represented. The measured resonance line shape plotted in Fig. 3(1) has two components: a symmetric or antidampinglike SOT (in-plane) and an antisymmetric or field-like SOT (perpendicular). Analysis of these FMR curves yields spin-charge conversion 
(a)

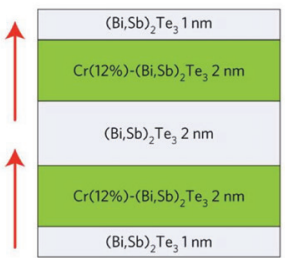

(c)

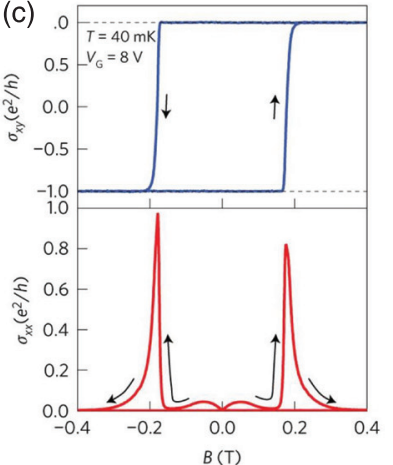

(e)

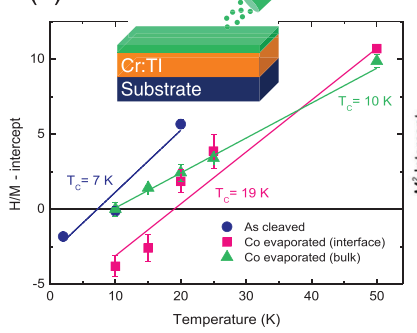

(b)

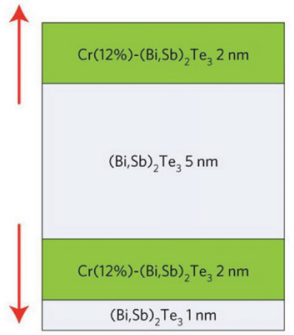

(d)

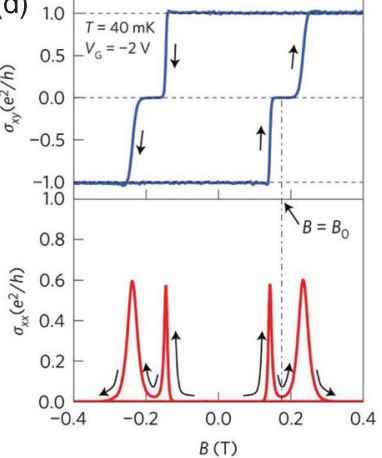

(f)

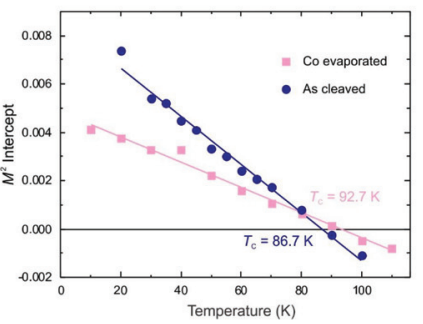

(g)

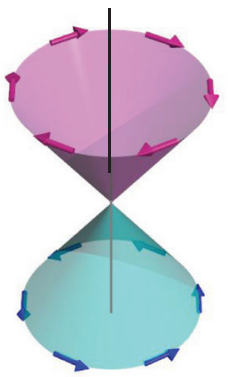

(h)
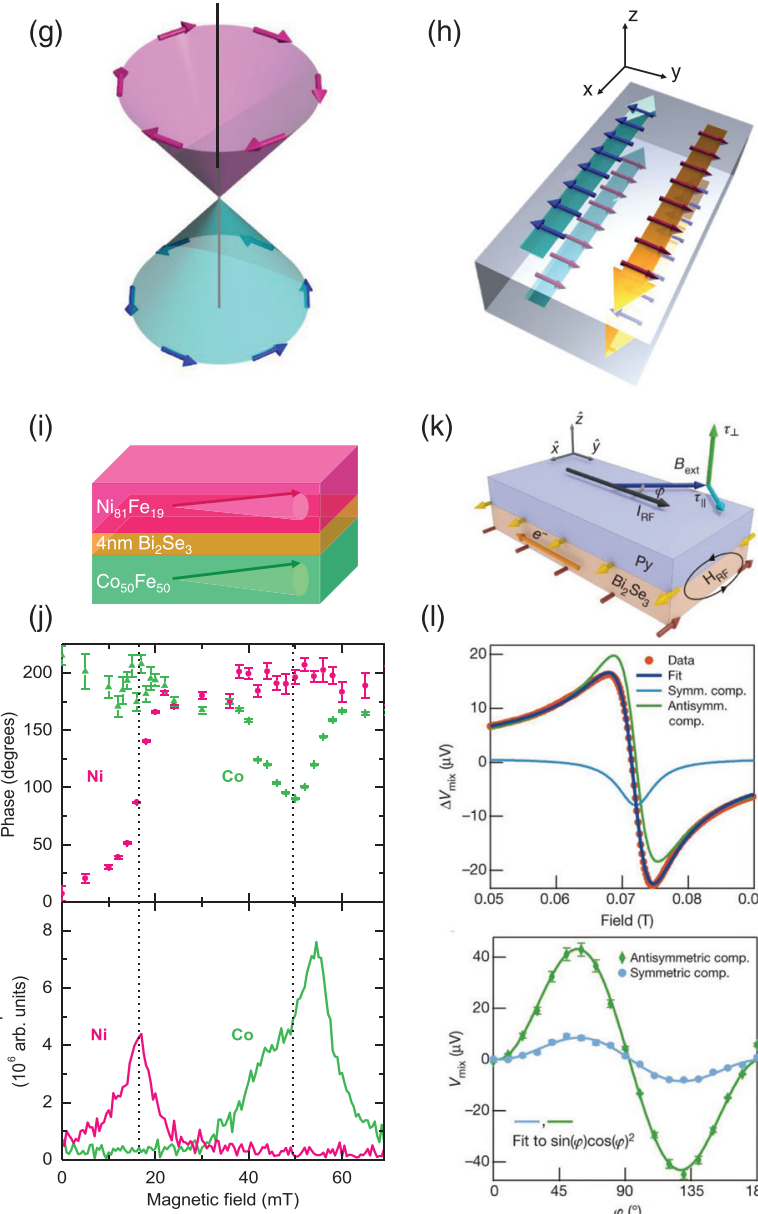

(k)

(I)
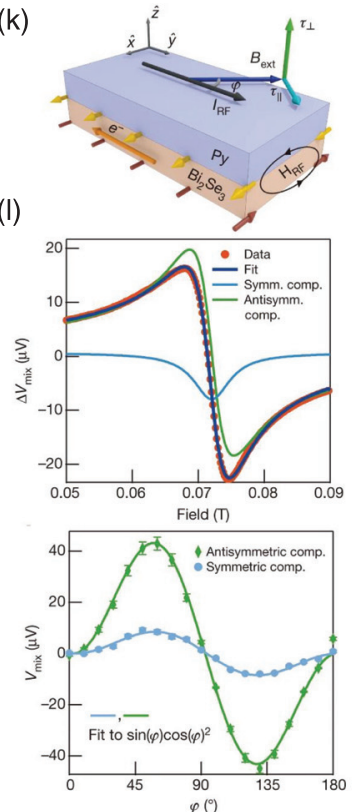

FIG. 3. Emergent phenomena in TI heterostructures. Schematic Cr-modulation-doped (a) quantum anomalous Hall and (b) axion insulators. Panels (c) and (d) show the magnetic field $(B)$ dependence of the Hall conductivity $\left(\sigma_{x y}\right)$ and longitudinal conductivity $\left(\sigma_{x x}\right)$ in the respective heterostructure films illustrated in (a) and (b). Panels (e) and (f) depict linear fits of parameters extracted from Arrott plots obtained from XMCD measurements in Cr-doped (e) $\mathrm{Bi}_{2} \mathrm{Se}_{3}$ and (f) $\mathrm{Sb}_{2} \mathrm{Te}_{3}$ thin films. The temperature at which the intercept goes through zero yields $T_{\mathrm{C}}$. The inset illustrates the process of in situ evaporation of a thin Co layer on top of the Cr-doped TI film. (g) Schematic illustration of the spin-momentum locked helical spin texture of the TSSs in a TI. (h) Schematic of surface spin density on two opposite surfaces of a TI thin film for a charge current flowing along the $-x$ direction and for a charge current flowing along the $+x$ direction. (i) Schematic of a FM/Bi $\mathrm{Se}_{3} / \mathrm{FM}$ heterostructure for spin pumping experiments with FMR and time-resolved FMR. (j) Phase (top panel) and amplitude (bottom panel) of precession of magnetization for Py (pink circles) and $\mathrm{Co}_{50} \mathrm{Fe}_{50}$ (green triangles) layers for $t_{\mathrm{Tl}}=$ $4 \mathrm{~nm}$. Dashed lines show the positions of the resonance amplitude peak. (k) Schematic diagram of SOT measurements in a $\mathrm{Py}_{\mathrm{Bi}} \mathrm{Se}_{3}$ bilayer. The yellow and red arrows denote spin moment directions. (I) Measured field dependent (top panel) spin-torque FMR at room temperature for a Py $(16 \mathrm{~nm}) / \mathrm{Bi}_{2} \mathrm{Se}_{3}(8 \mathrm{~nm})$ bilayer, together with fits of the symmetric and antisymmetric resonance components. Bottom panel: Measured dependence on the magnetic field angle $\varphi$ for the symmetric and antisymmetric resonance components. Panels (a)-(d) reprinted with permission from Mogi et al., Nat. Mater. 16, 516 (2017). Copyright 2017 Springer Nature. Panel (e) adapted and reprinted with permission from Baker et al., Phys. Rev. B 92, 094420 (2015). ${ }^{135}$ Copyright 2015 American Physical Society. Panel (f) adapted from Duffy et al., Phys. Rev. B 95 , 224422 (2017). Copyright 2017 Authors, licensed under a Creative Commons Attribution CC BY 4.0 license. Panels (i) and (j) reprinted with permission Figueroa et al., J. Magn. Magn. Mater. 400, 178 (2016). Copyright 2016 Elsevier. Panels (k)-(l) reprinted with permission from Mellnik et al., Nature 511, 449 (2014). Copyright 2014 Springer Nature.

parameters that are found to be much larger than those reported for heterostructures of FM with heavy metals. ${ }^{157}$ SOT in such FM/TI heterostructures can be used to efficiently manipulate the magnetization of the FM-a highly relevant feature for their applications in spintronic devices. Effective magnetization switching by SOT at room temperature has been demonstrated in, e.g., $\mathrm{Py} / \mathrm{Bi}_{2} \mathrm{Se}_{3},{ }^{160} \mathrm{CoTb} / \mathrm{Bi}_{2} \mathrm{Se}_{3}$, and $\mathrm{CoTb} /(\mathrm{Bi}, \mathrm{Sb})_{2} \mathrm{Te}_{3}$ structures. ${ }^{162}$

Despite the huge effort striving to make practical use of the quantum and spin phenomena at the surfaces and interfaces of TIs and despite the remarkable progress in the growth of thin films and complex heterostructures, there are a number of limitations intrinsic to these materials and many questions are still waiting to be addressed. Most of the experiments reviewed here rely on highly (charge) doped TIs in which the TSS coexist with bulk bands at the Fermi level, and for their analysis, it is assumed that the FM/TI interface is perfectly abrupt. However, magnetic phase segregation and interdiffusion are common issues in doped TIs and at FM/TI interfaces, and only recently, the systematic analysis of FM/TI interfaces has started, 
including practical strategies for improving their quality. ${ }^{161,163}$ The fact that the QAHE and other quantum, magnetoelectric, and spin phenomena continue to be only observable at very low temperatures can, in fact, be associated with this disorder at the topological interface. Therefore, there is a clear path to improve the quality of these systems, and there is still real potential for significantly increasing the energy and temperature scales at which these intriguing quantum effects can be observed, opening the door for useful quantum devices in the future. ${ }^{26}$ So, coming back to the question we raised in the abstract, i.e., whether there is hope for magnetically doped 3D TIs in the $(\mathrm{Sb}, \mathrm{Bi})_{2}(\mathrm{Se}, \mathrm{Te})_{3}$ family, we hope to have been able to provide some evidence for answering the question with a cautious "yes."

The authors express their deep gratitude to the medical care personnel during the Covid-19 pandemic. We acknowledge continuous support for the TI project at Oxford from the John Fell Fund (Oxford University Press), the synchrotron facilities Diamond Light Source, ALS, BESSYII, ALBA, and the ESRF and the neutron sources ISIS and ILL for beamtime leading to the reported insights. A.I.F. acknowledges funding from the European Union's Horizon 2020 research and innovation program under the Marie Skłodowska-Curie Grant Agreement No. 796925, the FET-PROACTIVE project TOCHA under Grant Agreement No. 824140 and the H2020 European Research Council PoC project SOTMEM under Grant Agreement 899896.

\section{DATA AVAILABILITY}

Data sharing is not applicable to this article as no new data were created or analyzed in this study.

\section{REFERENCES}

${ }^{1}$ L. Fu, C. L. Kane, and E. J. Mele, Phys. Rev. Lett. 98, 106803 (2007).

${ }^{2}$ H. J. Goldsmid and R. W. Douglas, Br. J. Appl. Phys. 5, 386 (1954).

${ }^{3}$ H. J. Goldsmid, A. R. Sheard, and D. A. Wright, Br. J. Appl. Phys. 9, 365 (1958).

${ }^{4}$ H. Zhang, C.-X. Liu, X.-L. Qi, X. Dai, Z. Fang, and S.-C. Zhang, Nat. Phys. 5, 438 (2009).

${ }^{5}$ Y. L. Chen, J. G. Analytis, J.-H. Chu, Z. K. Liu, S.-K. Mo, X.-L. Qi, H. J. Zhang, D. H. Lu, X. Dai, Z. Fang, S. C. Zhang, I. R. Fisher, Z. Hussain, and Z.-X. Shen, Science 325, 178 (2009)

${ }^{6}$ Y. S. Hor, A. Richardella, P. Roushan, Y. Xia, J. G. Checkelsky, A. Yazdani, M. Z. Hasan, N. P. Ong, and R. J. Cava, Phys. Rev. B 79, 195208 (2009).

${ }^{7}$ C.-Z. Chang, J. Zhang, X. Feng, J. Shen, Z. Zhang, M. Guo, K. Li, Y. Ou, P. Wei, L.-L. Wang, Z.-Q. Ji, Y. Feng, S. Ji, X. Chen, J. Jia, X. Dai, Z. Fang, S.-C. Zhang, K. He, Y. Wang, L. Lu, X.-C. Ma, and Q.-K. Xue, Science 340, 167 (2013).

${ }^{8}$ X.-L. Qi, T. L. Hughes, S. Raghu, and S.-C. Zhang, Phys. Rev. Lett. 102, 187001 (2009).

${ }^{9}$ X.-L. Qi and S. C. Zhang, Rev. Mod. Phys. 83, 1057 (2011).

${ }^{10}$ D. Pesin and A. H. MacDonald, Nat. Mater. 11, 409 (2012).

${ }^{11}$ C. Niu, Y. Dai, M. Guo, W. Wei, Y. Ma, and B. Huang, Appl. Phys. Lett. 98, 252502 (2011)

${ }^{12}$ M. Elkholdi, M. Averous, S. Charar, C. Fau, G. Brun, H. Ghoumaribouanani, and J. Deportes, Phys. Rev. B 49, 1711 (1994).

${ }^{13}$ Y. R. Song, F. Yang, M.-Y. Yao, F. Zhu, L. Miao, J.-P. Xu, M.-X. Wang, H. Li, X. Yao, F. Ji, S. Qiao, Z. Sun, G. B. Zhang, B. Gao, C. Liu, D. Qian, C. L. Gao, and J.-F. Jia, Appl. Phys. Lett. 100, 242403 (2012).

${ }^{14}$ S. E. Harrison, L. J. Collins-McIntyre, S. Li, A. A. Baker, L. R. Shelford, Y. Huo, A. Pushp, S. S. P. Parkin, J. S. Harris, E. Arenholz, G. van der Laan, and T. Hesjedal, J. Appl. Phys. 115, 023904 (2014).

${ }^{15}$ S. E. Harrison, L. J. Collins-McIntyre, S.-L. Zhang, A. A. Baker, A. I. Figueroa, A. J. Kellock, A. Pushp, S. S. P. Parkin, J. S. Harris, G. van der Laan, and T. Hesjedal, J. Phys.: Condens. Matter 27, 245602 (2015).
${ }^{16}$ S. E. Harrison, L. J. Collins-McIntyre, S.-L. Zhang, A. A. Baker, A. I. Figueroa, A. J. Kellock, A. Pushp, Y. Chen, S. S. P. Parkin, J. S. Harris, G. van der Laan, and T. Hesjedal, Appl. Phys. Lett. 107, 182406 (2015).

${ }^{17}$ S. E. Harrison, L. J. Collins-McIntyre, P. Schönherr, A. Vailionis, V. Srot, P. A. van Aken, A. J. Kellock, A. Pushp, S. S. P. Parkin, J. S. Harris, B. Zhou, Y. L. Chen, and T. Hesjedal, Sci. Rep. 5, 15767 (2015).

${ }^{18}$ L. J. Collins-McIntyre, S. E. Harrison, P. Schönherr, N.-J. Steinke, C. J. Kinane, T. R. Charlton, D. Alba-Veneroa, A. Pushp, A. J. Kellock, S. S. P. Parkin, J. S. Harris, S. Langridge, G. van der Laan, and T. Hesjedal, Europhys. Lett. 107, 57009 (2014).

${ }^{19}$ L. J. Collins-McIntyre, M. D. Watson, A. A. Baker, S. L. Zhang, A. I. Coldea, S. E. Harrison, A. Pushp, A. J. Kellock, S. S. P. Parkin, G. van der Laan, and T. Hesjedal, AIP Adv. 4, 127136 (2014).

${ }^{20}$ L. B. Duffy, A. I. Figueroa, L. Gładczuk, N.-J. Steinke, K. Kummer, G. van der Laan, and T. Hesjedal, Phys. Rev. B 95, 224422 (2017).

${ }^{21}$ Y. Deng, Y. Yu, M. Z. Shi, Z. Guo, Z. Xu, J. Wang, X. H. Chen, and Y. Zhang, Science 367, 895 (2020).

${ }^{22}$ C.-Z. Chang, J. Zhang, M. Liu, Z. Zhang, X. Feng, K. Li, L.-L. Wang, X. Chen, X. Dai, Z. Fang, X.-L. Qi, S.-C. Zhang, Y. Wang, K. He, X.-C. Ma, and Q.-K. Xue, Adv. Mater. 25, 1065 (2013).

${ }^{23}$ C.-Z. Chang, W. Zhao, D. Y. Kim, H. Zhang, B. A. Assaf, D. Heiman, S.-C. Zhang, C. Liu, M. H. W. Chan, and J. S. Moodera, Nat. Mater. 14, 473 (2015).

${ }^{24}$ Y. Tokura, K. Yasuda, and A. Tsukazaki, Nat. Rev. Phys. 1, 126 (2019).

${ }^{25} \mathrm{M}$. He, H. Sun, and Q. L. He, Front. Phys. 14, 43401 (2019).

${ }^{26}$ F. Fei, S. Zhang, M. Zhang, S. A. Shah, F. Song, X. Wang, and B. Wang, Adv. Mater. 32, 1904593 (2020).

${ }^{27}$ H. Köhler, Phys. Status Solidi B 58, 91 (1973).

${ }^{28}$ M. D. Watson, L. J. Collins-McIntyre, L. R. Shelford, A. I. Coldea, D. Prabhakaran, S. C. Speller, T. Mousavi, C. R. M. Grovenor, Z. Salman, S. R. Giblin, G. van der Laan, and T. Hesjedal, New J. Phys. 15, 103016 (2013).

${ }^{29}$ S. Li, M. S. Toprak, H. M. A. Soliman, J. Zhou, M. Muhammed, D. Platzek, and E. Mueller, Chem. Mater. 18, 3627 (2006).

${ }^{30}$ L. D. Alegria, M. D. Schroer, A. Chatterjee, G. R. Poirier, M. Pretko, S. K. Patel, and J. R. Petta, Nano Lett. 12, 4711 (2012).

${ }^{31}$ S. E. Harrison, P. Schoenherr, Y. Huo, J. S. Harris, and T. Hesjedal, Appl. Phys. Lett. 105, 153114 (2014).

${ }^{32}$ P. Schoenherr, D. Prabhakaran, W. Jones, N. Dimitratos, M. Bowker, and T. Hesjedal, Appl. Phys. Lett. 104, 253103 (2014).

${ }^{33}$ P. Schoenherr, L. J. Collins-Mclntyre, S. Zhang, P. Kusch, S. Reich, T. Giles, D. Daisenberger, D. Prabhakaran, and T. Hesjedal, Nanoscale Res. Lett. 9, 127 (2014).

${ }^{34}$ R. Cecchini, R. S. R. Gajjela, C. Martella, C. Wiemer, A. Lamperti, L. Nasi, L. Lazzarini, L. G. Nobili, and M. Longo, Small 15, 1901743 (2019).

${ }^{35} \mathrm{M}$. Ferhat, B. Liautard, G. Brun, J. Tedenac, M. Nouaoura, and L. Lassabatere, J. Cryst. Growth 167, 122 (1996).

${ }^{36}$ M. Ferhata, J. C. Tedenaca, and J. Nagaob, J. Cryst. Growth 218, 250 (2000).

${ }^{37}$ H. Cao, R. Venkatasubramanian, C. Liu, J. Pierce, H. Yang, M. Z. Hasan, Y. Wu, and Y. P. Chen, Appl. Phys. Lett. 101, 162104 (2012).

${ }^{38}$ W. J. Wang, K. H. Gao, and Z. Q. Li, Sci. Rep. 6, 25291 (2016).

${ }^{39}$ M. Rusek, T. Komossa, G. Bendt, and S. Schulz, J. Cryst. Growth 470, 128 (2017).

${ }^{40}$ Z. Liao, M. Brahlek, J. M. Ok, L. Nuckols, Y. Sharma, Q. Lu, Y. Zhang, and H. N. Lee, APL Mater. 7, 041101 (2019).

${ }^{41}$ E. Charles, E. Groubert, and A. Boyer, J. Mater. Sci. Lett. 7, 575 (1988).

${ }^{42}$ Y. Iwata, H. Kobayashi, S. Kikuchi, E. Hatta, and K. Mukasa, J. Cryst. Growth 203, 125 (1999).

${ }^{43}$ G. Wang, L. Endicott, and C. Uher, Sci. Adv. Mater. 3, 539 (2011).

${ }^{44}$ L. He, X. Kou, and K. L. Wang, Phys. Status Solidi RRL 7, 50 (2013).

${ }^{45}$ T. P. Ginley, Y. Wang, and S. Law, Crystals 6, 154 (2016).

${ }^{46}$ G. Zhang, H. Qin, J. Teng, J. Guo, Q. Guo, X. Dai, Z. Fang, and K. Wu, Appl. Phys. Lett. 95, 053114 (2009).

${ }^{47}$ Y.-Y. Li, G. Wang, X.-G. Zhu, M.-H. Liu, C. Ye, X. Chen, Y.-Y. Wang, K. He, L.-L. Wang, X.-C. Ma, H.-J. Zhang, X. Dai, Z. Fang, X.-C. Xie, Y. Liu, X.-L. Qi, J.-F. Jia, S.-C. Zhang, and Q.-K. Xue, Adv. Mater. 22, 4002 (2010).

${ }^{48}$ L. He, F. Xiu, Y. Wang, A. V. Fedorov, G. Huang, X. Kou, M. Lang, W. P. Beyermann, J. Zou, and K. L. Wang, J. Appl. Phys. 109, 103702 (2011).

${ }^{49}$ J. Krumrain, G. Mussler, S. Borisova, T. Stoica, L. Plucinski, C. Schneider, and D. Grützmacher, J. Cryst. Growth 324, 115 (2011). 
${ }^{50}$ X. Liu, D. J. Smith, J. Fan, Y.-H. Zhang, H. Cao, Y. P. Chen, J. Leiner, B. J. Kirby, M. Dobrowolska, and J. K. Furdyna, Appl. Phys. Lett. 99, 171903 (2011).

${ }^{51}$ X. Liu, D. J. Smith, H. Cao, Y. P. Chen, J. Fan, Y.-H. Zhang, R. E. Pimpinella, M. Dobrowolska, and J. K. Furdyna, J. Vac. Sci. Technol., B 30, 02 B103 (2012).

${ }^{52}$ A. A. Taskin, S. Sasaki, K. Segawa, and Y. Ando, Phys. Rev. Lett. 109, 066803 (2012).

${ }^{53}$ J. J. Lee, F. T. Schmitt, R. G. Moore, I. M. Vishik, Y. Ma, and Z. X. Shen, Appl. Phys. Lett. 101, 013118 (2012).

${ }^{54}$ N. Bansal, Y. S. Kim, M. Brahlek, E. Edrey, and S. Oh, Phys. Rev. Lett. 109, 116804 (2012).

${ }^{55}$ S. E. Harrison, S. Li, Y. Huo, B. Zhou, Y. L. Chen, and J. S. Harris, Appl. Phys. Lett. 102, 171906 (2013)

${ }^{56}$ Y. Zhao, C.-Z. Chang, Y. Jiang, A. DaSilva, Y. Sun, H. Wang, Y. Xing, Y. Wang, K. He, X. Ma, Q.-K. X. Xue, and J. Wang, Sci. Rep. 3, 3060 (2013).

${ }^{57}$ A. Richardella, D. M. Zhang, J. S. Lee, A. Koser, D. W. Rench, A. L. Yeats, B. B. Buckley, D. D. Awschalom, and N. Samarth, Appl. Phys. Lett. 97, 262104 (2010).

${ }^{58}$ Z. Chen, T. A. Garcia, J. De Jesus, L. Zhao, H. Deng, J. Secor, M. Begliarbekov, L. Krusin-Elbaum, and M. C. Tamargo, J. Electron. Mater. 43, 909 (2014).

${ }^{59} \mathrm{M}$. Eddrief, P. Atkinson, V. Etgens, and B. Jusserand, Nanotechnology 25, 245701 (2014)

${ }^{60}$ X. Liu, D. J. Smith, J. Fan, Y. Zhang, H. Cao, Y. P. Chen, B. J. Kirby, N. Sun, S. T. Ruggiero, J. Leiner, R. E. Pimpinella, J. Hagmann, K. Tivakornsasithorn, M. Dobrowolska, and J. K. Furdyna, AIP Conf. Proc. 1416, 105 (2011).

${ }^{61}$ T. Guillet, A. Marty, C. Beigne, C. Vergnaud, M. T. Dau, P. Noel, J. Frigerio, G. Isella, and M. Jamet, AIP Adv. 8, 115125 (2018).

${ }^{62}$ S. Kim, S. Lee, J. Woo, and G. Lee, Appl. Surf. Sci, 432, 152 (2018).

${ }^{63}$ X. F. Kou, L. He, F. X. Xiu, M. R. Lang, Z. M. Liao, Y. Wang, A. V. Fedorov, X. X. Yu, J. S. Tang, G. Huang, X. W. Jiang, J. F. Zhu, J. Zou, and K. L. Wang, Appl. Phys. Lett. 98, 242102 (2011).

${ }^{64}$ G. Zhang, H. Qin, J. Chen, X. He, L. Lu, Y. Li, and K. Wu, Adv. Funct. Mater. 21, 2351 (2011).

${ }^{65}$ Y. Zhang, K. He, C.-Z. Chang, C.-L. Song, L.-L. Wang, X. Chen, J.-F. Jia, Z. Fang, X. Dai, W.-Y. Shan, S.-Q. Shen, Q. Niu, X.-L. Qi, S.-C. Zhang, X.-C. Ma, and Q.-K. Xue, Nat. Phys. 6, 584 (2010).

${ }^{66}$ S. Schreyeck, N. V. Tarakina, G. Karczewski, C. Schumacher, T. Borzenko, C. Brune, H. Buhmann, C. Gould, K. Brunner, and L. W. Molenkamp, Appl, Phys. Lett. 102, 041914 (2013).

${ }^{67}$ X. Guo, Z. J. Xu, H. C. Liu, B. Zhao, X. Q. Dai, H. T. He, J. N. Wang, H. J. Liu, W. K. Ho, and M. H. Xie, Appl. Phys. Lett. 102, 151604 (2013).

${ }^{68}$ F. Bonell, M. G. Cuxart, K. Song, R. Robles, P. Ordejon, S. Roche, A. Mugarza, and S. O. Valenzuela, Cryst. Growth Des. 17, 4655 (2017).

${ }^{69}$ S. Jerng, K. Joo, Y. Kim, S. Yoon, J. Lee, M. Kim, J. Kim, E. Yoon, S. Chun, and Y. Kim, Nanoscale 5, 10618 (2013).

${ }^{70}$ N. Bansal, M. R. Cho, M. Brahlek, N. Koirala, Y. Horibe, J. Chen, W. Wu, Y. D. Park, and S. Oh, Nano Lett. 14, 1343 (2014).

${ }^{71}$ J. Jeon, M. Song, H. Kim, W. Jang, J. Park, S. Yoon, and S. Kahng, Appl. Surf. Sci. 316, 42 (2014)

${ }^{72}$ L. J. Collins-McIntyre, W. Wang, B. Zhou, S. C. Speller, Y. L. Chen, and T. Hesjedal, Phys. Status Solidi B 252, 1334 (2015).

${ }^{73}$ For achieving in-plane ordered films, the substrates should have hexagonal symmetry.

${ }^{74}$ A. Koma, K. Sunouchi, and T. Miyajima, J. Vac. Sci. Technol., B 3, 724 (1985).

${ }^{75}$ A. Koma, Thin Solids Films 216, 72 (1992).

${ }^{76}$ A. Koma, J. Cryst. Growth 201-202, 236 (1999).

${ }^{77}$ L. A. Walsh and C. L. Hinkle, Appl. Mater. Today 9, 504 (2017).

${ }^{78}$ X. Chen, X.-C. Ma, K. He, J.-F. Jia, and Q.-K. Xue, Adv. Mater. 23, 1162 (2011).

${ }^{79}$ A. A. Taskin, S. Sasaki, K. Segawa, and Y. Ando, Adv. Mater. 24, 5581 (2012).

${ }^{80}$ P. P. J. Haazen, J.-B. Laloë, T. J. Nummy, H. J. M. Swagten, P. Jarillo-Herrero, D. Heiman, and J. S. Moodera, Appl. Phys. Lett. 100, 082404 (2012).

${ }^{81}$ S. Li, S. Harrison, Y. Huo, A. Pushp, H. T. Yuan, B. Zhou, A. J. Kellock, S. S. P. Parkin, Y.-L. Chen, T. Hesjedal, and J. S. Harris, Appl. Phys. Lett. 102, $242412(2013)$
${ }^{82}$ K.-C. Kim, J. Lee, B. K. Kim, W. Y. Choi, H. J. Chang, S. O. Won, B. Kwon, S K. Kim, D.-B. Hyun, H. J. Kim, H. C. Koo, J.-H. Choi, D.-I. Kim, J.-S. Kim, and S.-H. Baek, Nat. Commun. 7, 12449 (2016).

${ }^{83}$ A. Karma and M. Plapp, Phys. Rev. Lett. 81, 4444 (1998).

${ }^{84}$ Y. Liu, M. Weinert, and L. Li, Phys. Rev. Lett. 108, 115501 (2012).

${ }^{85}$ R. Dingle, H. L. Störmer, A. C. Gossard, and W. Wiegmann, Appl. Phys. Lett. 33, 665 (1978).

${ }^{86}$ H. L. Störmer, A. Pinczuk, A. C. Gossard, and W. Wiegmann, Appl. Phys. Lett. 38, 691 (1981).

${ }^{87}$ R. O. Carlson, J. Phys. Chem. Solids 13, 65 (1960).

${ }^{88}$ M. A. Korzhuev and T. E. Svechnikov, Sov. Phys. Semicond. 25, 1288 (1991).

${ }^{89}$ K. J. Koski, C. D. Wessells, B. W. Reed, J. J. Cha, D. Kong, and Y. Cui, J. Am. Chem. Soc. 134, 13773 (2012).

${ }^{90}$ D. Music, X. Chen, D. M. Holzapfel, H. M. Bilyalova, M. Helvaci, A. O. D. Heymann, S. K. Aghda, T. Maron, A. L. Ravensburg, J. A. Sälker, L. Schnelle, and L. A. Woeste, J. Appl. Phys. 124, 185106 (2018).

${ }^{91}$ M. C. Shaughnessy, N. C. Bartelt, J. A. Zimmerman, and J. D. Sugar, J. Appl. Phys. 115, 063705 (2014).

${ }^{92}$ Y. C. Lan, D. Z. Wang, G. Chen, and Z. F. Ren, Appl. Phys. Lett. 92, 101910 (2008). 93. D. Keys and H. M. Dutton, J. Appl. Phys. 34, 1830 (1963).

${ }^{94}$ Z. Zhou, M. Zabeik, P. Lostak, and C. Uher, J. Appl. Phys. 99, 043901 (2006).

${ }^{95}$ Y. Sugama, T. Hayashi, H. Nakagawa, N. Miura, and V. A. Kulbachnskii, Low Temp. Phys. 298, 531 (2001).

${ }^{96}$ J. H. Rodriguez, Phys. Rev. B 100, 165113 (2019).

${ }^{97}$ V. Kulbachinskii, A. Y. Kaminskii, K. Kindo, Y. Narumi, K. Suga, P. Lostak, and P. Svanda, Physica B 311, 292 (2002).

${ }^{98}$ J. Teng, N. Liu, and Y. Li, J. Semicond. 40, 081507 (2019).

${ }^{99}$ J. Sánchez-Barriga, A. Varykhalov, G. Springholz, H. Steiner, R. Kirchschlager, G. Bauer, O. Caha, E. Schierle, E. Weschke, A. A. Ünal, S. Valencia, M. Dunst, J. Braun, H. Ebert, J. Minár, E. Golias, L. V. Yashina, A. Ney, V. Holý, and O. Rader, Nat. Commun. 7, 10559 (2016).

${ }^{100}$ M. M. Otrokov, I. I. Klimovskikh, H. Bentmann, D. Estyunin, A. Zeugner, Z. S. Aliev, S. Gaß, A. U. B. Wolter, A. V. Koroleva, A. M. Shikin, M. BlancoRey, M. Hoffmann, A. Y. Rusinov, I. P. Vyazovskaya, S. V. Eremeev, Y. M. Koroteev, V. M. Kuznetsov, F. Freyse, J. Sánchez-Barriga, I. R. Amiraslanov, M. B. Babanly, N. T. Mamedov, N. A. Abdullayev, V. N. Zverev, A. Alfonsov, V. Kataev, B. Büchner, E. F. Schwier, S. Kumar, A. Kimura, L. Petaccia, G. D. Santo, R. C. Vidal, S. Schatz, K. Kißner, M. Ünzelmann, C. H. Min, S. Moser, T. R. F. Peixoto, F. Reinert, A. Ernst, P. M. Echenique, A. Isaeva, and E. V. Chulkov, Nature 576, 416 (2019).

${ }^{101}$ M. Ye, W. Li, S. Zhu, Y. Takeda, Y. Saitoh, J. Wang, H. Pan, M. Nurmamat, K. Sumida, F. Ji, Z. Liu, H. Yang, Z. Liu, D. Shen, A. Kimura, S. Qiao, and X. Xie, Nat. Commun. 6, 8913 (2015).

${ }^{102}$ N.-J. Steinke, S. L. Zhang, L. B. Duffy, F. Kronast, Z. Salman, T. Prokscha, A. Suter, S. Langridge, G. van der Laan, and T. Hesjedal (unpublished) (2020).

${ }^{103}$ E. O. Lachman, A. F. Young, A. Richardella, J. Cuppens, H. R. Naren, Y. Anahory, A. Y. Meltzer, A. Kandala, S. Kempinger, Y. Myasoedov, M. E. Huber, N. Samarth, and E. Zeldov, Sci. Adv. 1, e1500740 (2015).

${ }^{104}$ W. Liu, Y. Xu, L. He, G. van der Laan, R. Zhang, and K. Wang, Sci. Adv. 5 eaav2088 (2019).

${ }^{105}$ L. J. Collins-McIntyre, L. B. Duffy, A. Singh, N.-J. Steinke, C. J. Kinane, T. R. Charlton, A. Pushp, A. J. Kellock, S. S. P. Parkin, S. N. Holmes, C. H. W. Barnes, G. van der Laan, S. Langridge, and T. Hesjedal, Europhys. Lett. 115, 27006 (2016).

${ }^{106}$ A. Tcakaev, V. B. Zabolotnyy, R. J. Green, T. R. Peixoto, F. Stier, M. Dettbarn, S. Schreyeck, M. Winnerlein, R. C. Vidal, S. Schatz, H. B. Vasili, M. Valvidares, K. Brunner, C. Gould, H. Bentmann, F. Reinert, L. W. Molenkamp, and V. Hinkov, Phys. Rev. B 101, 045127 (2020).

${ }^{107}$ L. Zhang, D. Zhao, Y. Zang, Y. Yuan, G. Jiang, M. Liao, D. Zhang, K. He, X. Ma, and Q. Xue, APL Mater. 5, 076106 (2017).

${ }^{108}$ J. S. Lee, A. Richardella, D. W. Rench, R. D. Fraleigh, T. C. Flanagan, J. A. Borchers, J. Tao, and N. Samarth, Phys, Rev. B 89, 174425 (2014).

${ }^{109}$ A. I. Figueroa, G. van der Laan, L. J. Collins-McIntyre, G. Cibin, A. J. Dent, and T. Hesjedal, J. Phys. Chem. C 119, 17344 (2015).

${ }^{110}$ J. Růžička, O. Caha, V. Holý, H. Steiner, V. Volobuiev, A. Ney, G. Bauer, T. Duchoň, K. Veltruská, I. Khalakhan, V. Matolín, E. F. Schwier, H. Iwasawa, K. Shimada, and G. Springholz, New J. Phys. 17, 013028 (2015). 
${ }^{m}$ A. I. Figueroa, G. van der Laan, S. E. Harrison, G. Cibin, and T. Hesjedal, Sci. Rep. 6, 22935 (2016).

${ }^{112} \mathrm{H}$. D. Li, Z. Y. Wang, X. Kan, X. Guo, H. T. He, Z. Wang, J. N. Wang, T. L. Wong, N. Wang, and M. H. Xie, New J. Phys. 12, 103038 (2010).

${ }^{113}$ C. I. Fornari, H. Bentmann, S. L. Morelhao, T. R. F. Peixoto, P. H. O. Rappl, A.-V. Tcakaev, V. Zabolotnyy, M. Kamp, T.-L. Lee, C.-H. Min, P. Kagerer, R. C. Vidal, A. Isaeva, M. Ruck, V. Hinkov, F. Reinert, and E. Abramof, J. Phys. Chem. C 124, 16048 (2020).

${ }^{114}$ B. A. Aronzon, L. N. Oveshnikov, V. A. Prudkoglyad, Y. G. Selivanov, E. G. Chizhevskii, K. I. Kugel, I. A. Karateev, A. L. Vasiliev, and E. Lähderanta, J. Magn. Magn. Mater. 459, 331 (2018).

${ }^{115}$ R. Yu, W. Zhang, H.-J. Zhang, S.-C. Zhang, X. Dai, and Z. Fang, Science 329, 61 (2010).

${ }^{116}$ M. Li, C. Z. Chang, L. Wu, J. Tao, W. Zhao, M. H. Chan, J. S. Moodera, J. Li, and Y. Zhu, Phys. Rev. Lett. 114, 146802 (2015).

${ }^{117}$ J. H. Van Vleck, Rev. Mod. Phys. 25, 220 (1953).

${ }^{118}$ M. F. Islam, C. M. Canali, A. Pertsova, A. Balatsky, S. K. Mahatha, C. Carbone, A. Barla, K. A. Kokh, O. E. Tereshchenko, E. Jiménez, N. B. Brookes, P. Gargiani, M. Valvidares, S. Schatz, T. R. Peixoto, H. Bentmann, F. Reinert, J. Jung, T. Bathon, K. Fauth, M. Bode, and P. Sessi, Phys. Rev. B 97, 155429 (2018).

${ }^{119}$ M. G. Vergniory, M. M. Otrokov, D. Thonig, M. Hoffmann, I. V. Maznichenko, M. Geilhufe, X. Zubizarreta, S. Ostanin, A. Marmodoro, J. Henk, W. Hergert, I. Mertig, E. V. Chulkov, and A. Ernst, Phys. Rev. B 89, 165202 (2014).

${ }^{120}$ M. Ye, T. Xu, G. Li, S. Qiao, Y. Takeda, Y. Saitoh, S. Y. Zhu, M. Nurmamat, K. Sumida, Y. Ishida, S. Shin, and A. Kimura, Phys. Rev. B 99, 144413 (2019).

${ }^{121}$ T. Dietl, H. Ohno, F. Matsukura, J. Cibert, and D. Ferrand, Science 287, 1019 (2000).

${ }^{122}$ V. G. Storchak, D. G. Eshchenko, E. Morenzoni, T. Prokscha, A. Suter, X. Liu, and J. K. Furdyna, Phys. Rev. Lett. 101, 027202 (2008).

${ }^{123}$ L. Fang, Y. Jia, D. J. Miller, M. L. Latimer, Z. L. Xiao, U. Welp, G. W. Crabtree, and W.-K. Kwok, Nano Lett. 12, 6164 (2012).

${ }^{124}$ J. A. Krieger, Y. Ou, M. Caputo, A. Chikina, M. Döbeli, M.-A. Husanu, I. Keren, T. Prokscha, A. Suter, C.-Z. Chang, J. S. Moodera, V. N. Strocov, and Z. Salman, Phys. Rev. B 99, 064423 (2019).

${ }^{125}$ J. Fujii, M. Sperl, S. Ueda, K. Kobayashi, Y. Yamashita, M. Kobata, P. Torelli, F. Borgatti, M. Utz, C. S. Fadley, A. X. Gray, G. Monaco, C. H. Back, G. van der Laan, and G. Panaccione, Phys. Rev. Lett. 107, 187203 (2011).

${ }^{126}$ D. J. Priour and S. D. Sarma, Phys. Rev. B 73, 165203 (2006).

${ }^{127}$ A. I. Figueroa, A. A. Baker, S. Harrison, K. Kummer, G. van der Laan, and T. Hesjedal, J. Magn. Magn. Mater. 422, 93 (2017).

${ }^{128}$ L. B. Duffy, N.-J. Steinke, J. A. Krieger, A. I. Figueroa, K. Kummer, T. Lancaster, S. R. Giblin, F. L. Pratt, S. J. Blundell, T. Prokscha, A. Suter, S. Langridge, V. N. Strocov, Z. Salman, G. van der Laan, and T. Hesjedal, Phys. Rev. B 97, 174427 (2018)

${ }^{129}$ L. B. Duffy, A. Frisk, D. M. Burn, N.-J. Steinke, J. Herrero-Martin, A. Ernst, G. van der Laan, and T. Hesjedal, Phys. Rev. Mater. 2, 054201 (2018).

${ }^{130}$ L. B. Duffy, N. J. Steinke, D. M. Burn, A. Frisk, L. Lari, B. Kuerbanjiang, V. K. Lazarov, G. van der Laan, S. Langridge, and T. Hesjedal, Phys. Rev. B 100, 054402 (2019).

${ }^{131}$ M. Mogi, R. Yoshimi, A. Tsukazaki, K. Yasuda, Y. Kozuka, K. S. Takahashi, M. Kawasaki, and Y. Tokura, Appl. Phys. Lett. 107, 182401 (2015).

${ }^{132}$ M. Mogi, M. Kawamura, R. Yoshimi, A. Tsukazaki, Y. Kozuka, N. Shirakawa, K. S. Takahashi, M. Kawasaki, and Y. Tokura, Nat. Mater. 16, 516 (2017).

${ }^{133}$ W. Liu, L. He, Y. Xu, K. Murata, M. C. Onbasli, M. Lang, N. J. Maltby, S. Li, X. Wang, C. A. Ross, P. Bencok, G. van der Laan, R. Zhang, and K. L. Wang, Nano Lett. 15, 764 (2015)

${ }^{134}$ I. Vobornik, U. Manju, J. Fujii, F. Borgatti, P. Torelli, D. Krizmancic, Y. S. Hor, R. J. Cava, and G. Panaccione, Nano Lett. 11, 4079 (2011).

${ }^{135}$ A. A. Baker, A. I. Figueroa, K. Kummer, L. J. Collins-McIntyre, T. Hesjedal, and G. van der Laan, Phys. Rev. B 92, 094420 (2015).

${ }^{136}$ T. Hesjedal and Y. Chen, Nat. Mater. 16, 3 (2017).

${ }^{137}$ Q. L. He, X. Kou, A. J. Grutter, G. Yin, L. Pan, X. Che, Y. Liu, T. Nie, B. Zhang, S. M. Disseler, B. J. Kirby, W. Ratcliff II, Q. Shao, K. Murata, X. Zhu, G. Yu, Y. Fan, M. Montazeri, X. Han, J. A. Borchers, and K. L. Wang, Nat. Mater. 16, 94 (2017).
${ }^{138}$ M. M. Otrokov, T. V. Menshchikova, I. P. Rusinov, M. G. Vergniory, V. M. Kuznetsov, and E. V. Chulkov, JETP Lett. 105, 297 (2017).

${ }^{139}$ M. M. Otrokov, T. V. Menshchikova, M. G. Vergniory, I. P. Rusinov, A. Y. Vyazovskaya, Y. M. Koroteev, G. Bihlmayer, A. Ernst, P. M. Echenique, A. Arnau, and E. V. Chulkov, 2D Mater. 4, 025082 (2017).

${ }^{140}$ T. Hirahara, S. V. Eremeev, T. Shirasawa, Y. Okuyama, T. Kubo, R. Nakanishi, R. Akiyama, A. Takayama, T. Hajiri, S.-I. Ideta, M. Matsunami, K. Sumida, K. Miyamoto, Y. Takagi, K. Tanaka, T. Okuda, T. Yokoyama, S.-I. Kimura, S. Hasegawa, and E. V. Chulkov, Nano Lett. 17, 3493 (2017).

${ }^{141}$ S. V. Eremeev, M. M. Otrokov, and E. V. Chulkov, Nano Lett. 18, 6521 (2018).

${ }^{142}$ I. I. Klimovskikh, M. M. Otrokov, D. Estyunin, S. V. Eremeev, S. O. Filnov, A. Koroleva, E. Shevchenko, V. Voroshnin, A. G. Rybkin, I. P. Rusinov, M. Blanco-Rey, M. Hoffmann, Z. S. Aliev, M. B. Babanly, I. R. Amiraslanov, N. A. Abdullayev, V. N. Zverev, A. Kimura, O. E. Tereshchenko, K. A. Kokh, L. Petaccia, G. D. Santo, A. Ernst, P. M. Echenique, N. T. Mamedov, A. M. Shikin, and E. V. Chulkov, npj Quantum Mater. 5, 54 (2020).

${ }^{143}$ P. Wei, F. Katmis, B. A. Assaf, H. Steinberg, P. Jarillo-Herrero, D. Heiman, and J. S. Moodera, Phys. Rev. Lett. 110, 186807 (2013).

${ }^{144}$ F. Katmis, V. Lauter, F. S. Nogueira, B. A. Assaf, M. E. Jamer, P. Wei, B. Satpati, J. W. Freeland, I. Eremin, D. Heiman, P. Jarillo-Herrero, and J. S. Moodera, Nature 533, 513 (2016).

${ }^{145}$ C. Lee, F. Katmis, P. Jarillo-Herrero, J. S. Moodera, and N. Gedik, Nat. Commun. 7, 12014 (2016).

${ }^{146}$ Z. Jiang, C.-Z. Chang, C. Tang, P. Wei, J. S. Moodera, and J. Shi, Nano Lett. 15, 5835 (2015).

${ }^{147}$ M. Li, Q. Song, W. Zhao, J. A. Garlow, T.-H. Liu, L. Wu, Y. Zhu, J. S. Moodera, M. H. W. Chan, G. Chen, and C.-Z. Chang, Phys. Rev. B 96, 201301 (2017).

${ }^{148}$ C. Tang, C.-Z. Chang, G. Zhao, Y. Liu, Z. Jiang, C.-X. Liu, M. R. McCartney, D. J. Smith, T. Chen, J. S. Moodera, and J. Shi, Sci. Adv. 3, el700307 (2017).

${ }^{149}$ M. Mogi, T. Nakajima, V. Ukleev, A. Tsukazaki, R. Yoshimi, M. Kawamura, K. S. Takahashi, T. Hanashima, K. Kakurai, T.-H. Arima, M. Kawasaki, and Y. Tokura, Phys. Rev. Lett. 123, 016804 (2019).

${ }^{150}$ R. Watanabe, R. Yoshimi, M. Kawamura, M. Mogi, A. Tsukazaki, X. Z. Yu, K. Nakajima, K. S. Takahashi, M. Kawasaki, and Y. Tokura, Appl. Phys. Lett. 115, 102403 (2019).

${ }^{151}$ V. M. Pereira, S. G. Altendorf, C. E. Liu, S. C. Liao, A. C. Komarek, M. Guo, H.-J. Lin, C. T. Chen, M. Hong, J. Kwo, L. H. Tjeng, and C. N. Wu, Phys. Rev Mater. 4, 064202 (2020).

${ }^{152}$ Y. Shiomi, K. Nomura, Y. Kajiwara, K. Eto, M. Novak, K. Segawa, Y. Ando, and E. Saitoh, Phys. Rev. Lett. 113, 196601 (2014).

${ }^{153}$ A. A. Baker, A. I. Figueroa, L. J. Collins-McIntyre, G. van der Laan, and T. Hesjedal, Sci. Rep, 5, 7907 (2015).

${ }^{154}$ M. Jamali, J. S. Lee, J. S. Jeong, F. Mahfouzi, Y. Lv, Z. Zhao, B. K. Nikolic, K. A. Mkhoyan, N. Samarth, and J.-P. Wang, Nano Lett. 15, 7126 (2015).

${ }^{155}$ A. I. Figueroa, A. A. Baker, L. J. Collins-McIntyre, T. Hesjedal, and G. van der Laan, J. Magn. Magn. Mater. 400, 178 (2016).

${ }^{156}$ A. A. Baker, A. I. Figueroa, T. Hesjedal, and G. van der Laan, J. Magn. Magn. Mater. 473, 470 (2019)

${ }^{157}$ A. R. Mellnik, J. S. Lee, A. Richardella, J. L. Grab, P. J. Mintun, M. H. Fischer, A. Vaezi, A. Manchon, E.-A. Kim, N. Samarth, and D. Ralph, Nature 511, 449 (2014).

${ }^{158}$ Y. Wang, P. Deorani, K. Banerjee, N. Koirala, M. Brahlek, S. Oh, and H. Yang, Phys. Rev. Lett. 114, 257202 (2015)

${ }^{159}$ J.-C. Rojas-Sánchez, S. Oyarzún, Y. Fu, A. Marty, C. Vergnaud, S. Gambarelli, L. Vila, M. Jamet, Y. Ohtsubo, A. Taleb-Ibrahimi, P. Le Fèvre, F. Bertran, N. Reyren, J.-M. George, and A. Fert, Phys. Rev. Lett. 116, 096602 (2016).

${ }^{160}$ Y. Wang, D. Zhu, Y. Wu, Y. Yang, J. Yu, R. Ramaswamy, R. Mishra, S. Shi, M. Elyasi, K.-L. Teo, Y. Wu, and H. Yang, Nat. Commun. 8, 1364 (2017).

${ }^{161}$ H. Wu, P. Zhang, P. Deng, Q. Lan, Q. Pan, S. A. Razavi, X. Che, L. Huang, B. Dai, K. Wong, X. Han, and K. L. Wang, Phys. Rev. Lett. 123, 207205 (2019).

${ }^{162}$ J. Han, A. Richardella, S. A. Siddiqui, J. Finley, N. Samarth, and L. Liu, Phys. Rev. Lett. 119, 077702 (2017)

${ }^{163}$ F. Bonell, M. Goto, G. Sauthier, J. F. Sierra, A. I. Figueroa, M. V. Costache, S. Miwa, Y. Suzuki, and S. O. Valenzuela, Nano Lett. 20, 5893 (2020). 